\title{
Synthesis and characterization of 5-(2-fluoro-4-[11C]methoxyphenyl)-2,2-dimethyl-3,4- dihydro-2H-pyrano[2,3-b]pyridine-7-carboxamide as a PET imaging ligand for metabotropic glutamate receptor 2
}

Gengyang Yuan,,$^{\dagger}{ }^{*}$ Maeva Dhaynaut, ${ }^{\dagger}$ Yu Lan, ${ }^{\ddagger}$ Nicolas J. Guehl, ${ }^{\dagger}$ Dalena Huynh, ${ }^{\dagger}$ Suhasini

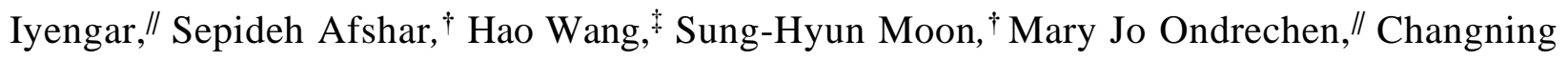
Wang,${ }^{\dagger}$ Timothy Shoup,${ }^{\dagger}$ Georges El Fakhri, ${ }^{\dagger}$ Marc D. Normandin,${ }^{\dagger}$ Anna-Liisa Brownell ${ }^{\dagger}, *$

${ }^{\dagger}$ Gordon Center for Medical Imaging, Massachusetts General Hospital and Harvard Medical School, $3^{\text {rd }}$ Avenue, Charlestown, MA 02129, USA

${ }^{\ddagger}$ Athinoula A. Martinos Center for Biomedical Imaging, Massachusetts General Hospital and Harvard Medical School, Charlestown, Massachusetts 02129, USA

"Department of Chemistry and Chemical Biology, Northeastern University, 360 Huntington Avenue, Boston, MA 02115, USA

\section{Corresponding Authors}

*G.Y.: phone 857-210-6386; email, gyyuan@mgh.harvard.edu; ORCID ID:

https://orcid.org/0000-0003-4817-0052

*A-L.B.: phone 617-744-3725; email, abrownell@ mgh.harvard.edu; ORCID ID: https://orcid.org/0000-0002-3814-868X 


\begin{abstract}
Metabotropic glutamate receptor 2 (mGluR2) is a therapeutic target for the treatment of several neuropsychiatric disorders and conditions. The role of mGluR2 function in etiology could be unveiled by in vivo imaging using positron emission tomography (PET). In this regard, 5-(2fluoro-4-[ $\left.{ }^{11} \mathrm{C}\right]$ methoxyphenyl)-2,2-dimethyl-3,4-dihydro-2H-pyrano[2,3-b]pyridine-7-

carboxamide $\left(\left[{ }^{11} \mathrm{C}\right] \mathbf{1 3}\right)$, a potent negative allosteric modulator (NAM), was developed to support this endeavor. Radioligand $\left[{ }^{11} \mathrm{C}\right] 13$ was synthesized via the $O-\left[{ }^{11} \mathrm{C}\right]$ methylation of phenol 24 with a high molar activity of $212 \pm 76 \mathrm{GBq} / \mu \mathrm{mol}(\mathrm{n}=5)$ and excellent radiochemical purity $(>99 \%)$ PET imaging of $\left[{ }^{11} \mathrm{C}\right] \mathbf{1 3}$ in rats demonstrated its superior brain heterogeneity, particularly in the regions of striatum, thalamus, hippocampus, and cortex. Accumulation of $\left[{ }^{11} \mathrm{C}\right] \mathbf{1 3}$ in these regions of interest (ROIs) was reduced with pretreatment of mGluR2 NAMs, VU6001966 (9) and MNI137 (26), the extent of which revealed a time-dependent drug effect of the blocking agents. In a nonhuman primate, $\left[{ }^{11} \mathrm{C}\right] \mathbf{1 3}$ selectively accumulated in mGluR2-rich regions, especially in different cortical areas, putamen, thalamus, and hippocampus, and resulted in high-contrast brain images. The regional total volume of distribution $\left(V_{T}\right)$ estimates of $\left[{ }^{11} \mathrm{C}\right] \mathbf{1 3}$ decreased by $14 \%$ after the pretreatment with 9 . Therefore, $\left[{ }^{11} \mathrm{C}\right] \mathbf{1 3}$ is a potential candidate for translational PET imaging studies of mGluR2 function.
\end{abstract}

Keywords: kinetic modeling, metabotropic glutamate receptor, negative allosteric modulator, non-human primate, positron emission tomography 


\section{INTRODUCTION}

As the most abundant endogenous neurotransmitter in the central nervous system (CNS), glutamate has an important role in regulating several neurological functions in the brain. ${ }^{1-}$

${ }^{2}$ There are two families of glutamate receptors, namely the ionotropic glutamate receptors (iGluRs) and the metabotropic glutamate receptors (mGluRs). ${ }^{3}$ The mGluRs are further divided into three groups based on their sequence homology, pharmacological effects, and distribution. ${ }^{4}$ Among them, the group II mGluRs, including mGluR2 and mGluR3, are promising targets for drug discovery, especially for the treatment of schizophrenia, ${ }^{5-6}$ anxiety, ${ }^{7-8}$ depression, ${ }^{9}$ pain, ${ }^{10}$ and Alzheimer's disease ${ }^{11}$. The rationale is that mGluR2 and mGluR3 are highly distributed in the forebrain at the presynaptic nerve terminals and activation of these receptors reduces the excessive glutamatergic signaling that is implicated in the pathophysiology of these diseases. ${ }^{9,12}$ Despite the setback of LY2140023, ${ }^{6}$ a group II agonist prodrug, in clinical trials for the treatment of schizophrenia, ${ }^{13-14}$ it demonstrated the disease-modifying potential of targeting the mGluR2focused glutamatergic signaling and emphasized the importance of mGluR2-subtype selectivity for successful drug candidates. ${ }^{15-16}$ As a result, allosteric modulators that bind to the more lipophilic and structurally less conserved seven transmembrane (7-TM) region are developed to afford ligands with more favorable physiochemical properties and enhanced selectivity for mGluR2 binding. ${ }^{17-18}$ Similarly, development of positron emission tomography (PET) radioligands targeting mGluR2 have shifted from the early group II orthosteric ligands, such as the mGluR2/3 antagonists $\left[{ }^{11} \mathrm{C}\right] \mathrm{MMMHC}(\mathbf{1})^{19}$ and $\left[{ }^{11} \mathrm{C}\right] \mathrm{CMGDE}(\mathbf{2})^{20}$, to the recent allosteric modulators-derived radiotracers, such as the positive allosteric modulators (PAMs) of $\left[{ }^{11} \mathrm{C}\right] \mathrm{JNJ}-$ $42491293(\mathbf{3})^{21},\left[{ }^{11} \mathrm{C}\right] \mathrm{mG} 2 \mathrm{P} 001(\mathbf{4}),{ }^{22-23}\left[{ }^{18} \mathrm{~F}\right] \mathrm{JNJ}-46356479(5)^{24}$ and $\left[{ }^{18} \mathrm{~F}\right] \mathrm{mG} 2 \mathrm{P} 026(\mathbf{6})^{25}$ (Fig. 1). 
As a non-invasive in vivo imaging technique, PET will enable the visualization and quantification of mGluR2 under normal and disease conditions as well as the evaluation of target engagement and the dose occupancy studies of drug candidates. Currently, there is no suitable mGluR2 PET tracer for humans. $\left[{ }^{11} \mathrm{C}\right] \mathrm{JNJ}-42491293$ (3), the only structurally disclosed PET tracer that entered clinical trials, showed unexpected binding in the myocardium and off-target binding in the brain. ${ }^{21}$ Besides our current efforts of developing a new series of mGluR2 PAM radiotracers for clinical use, ${ }^{22-25}$ we are also devoted to identifying negative allosteric modulators (NAMs)based radiotracers due to their distinct allosteric mode of action and pharmacology. ${ }^{26-29}$ As noted by O'Brien et al, mGluR2 PAMs had both affinity and efficacy cooperativity with glutamate, whereas mGluR2 NAMs showed predominantly efficacy cooperativity. ${ }^{26}$ The development of NAM-based PET tracers is still nascent without any viable tracers reported in higher species. At the beginning of our work, only $\left[{ }^{11} \mathrm{C}\right] \mathrm{QCA}\left(7, \mathrm{IC}_{50}=45 \mathrm{nM}\right)^{30}$ and $\left[{ }^{11} \mathrm{C}\right] \mathrm{MMP}\left(8, \mathrm{IC}_{50}=59 \mathrm{nM}\right)^{31}$ were disclosed. However, these tracers suffered poor brain permeability in rats with a SUV $\mathrm{max}_{\mathrm{m}}$ value of 0.3 and 0.7 , respectively. Further studies of these radiotracers in the P-glycoprotein and the breast cancer resistance protein (Pgp-BCRP) knock-out mouse model indicated that they are likely substrates of the efflux pumps on the blood-brain barrier (BBB). ${ }^{30-31} \mathrm{QCA}(7)$ was presented in a patent application filed by Merck Research Laboratories in $2013^{32}$ and the structure-activity relationship was further explored by Felts et al in $2015 .{ }^{33}$ Compound MMP (8) is an analogous NAM of VU6001966 $\left(\mathbf{9}, \mathrm{IC}_{50}=78 \mathrm{nM}\right)^{34}$, developed by Bollinger et al, has higher brain permeability than QCA (7), thus it was deemed as a promising PET imaging candidate. ${ }^{34}$ However, according to the recent publication, the ${ }^{11} \mathrm{C}$-labeled VU6001966 (9) has the same issues as $\left[{ }^{11} \mathrm{C}\right] \mathrm{QCA}(7) .{ }^{35}$ Since there are no explanations on the structural basis of the poor brain permeability for these NAM tracers, we searched for a completely new chemical scaffold to avoid 
this issue. The recent surge on the development of mGluR2 NAMs has resulted in a number of patent applications and research publications, providing an ample reservoir of PET imaging candidates with distinct structures. For instance, the recently published NAM tracers of $\left[{ }^{11} \mathrm{C}\right] \mathrm{MG}-$ $1904\left(\mathbf{1 0}, \mathrm{IC}_{50}=24 \mathrm{nM}\right),{ }^{36}$ which was selected from a series of tetrahydronaphthyridine derivatives patented by Merck in 2016, ${ }^{37}$ and $\left[{ }^{11} \mathrm{C}\right] \mathrm{MG} 2-1812\left(\mathbf{1 1}, \mathrm{IC}_{50}=21 \mathrm{nM}\right),{ }^{35}$ which was a close analog of VU6001966 (9), ${ }^{34}$ were brain permeable in rats.

After a comprehensive examination of the chemical scaffolds, we selected the 3,4-dihydro- $2 H$ pyrano[2,3-b]pyridine derivative, 5-(2,4-difluorophenyl)-2,2-dimethyl-3,4-dihydro-2H-pyrano [2,3-b]pyridine-7-carboxamide (12), as a lead compound. Compound $\mathbf{1 2}$ was reported as a potent mGluR2 NAM $\left(\mathrm{IC}_{50}=6.0 \mathrm{nM}\right)$ by Merck in $2018 .{ }^{38}$ Although only limited information was provided for compound 12, we envisioned this compound to be an ideal starting point due to its potent modulatory affinity, absence of a chiral center, and ease to introduce structural variances for future structure-activity analysis (SAR). As a proof-of-concept study, compound $\mathbf{1 2}$ and/or its analogs are expected to be radiolabeled with convenient methods to allow a rapid PET imaging evaluation of their brain permeability and kinetics. With this in mind, replacement of the parafluoride at compound $\mathbf{1 2}$ with a phenolic methyl ether led to the 5-(2-fluoro-4-methoxyphenyl)2,2-dimethyl-3,4-dihydro-2H-pyrano[2,3-b]pyridine-7-carboxamide $\quad(\mathbf{1 3}) . \quad$ This chemical modification allowed the radiolabeling of $\mathbf{1 3}$ with $\left[{ }^{11} \mathrm{C}\right] \mathrm{CH}_{3} \mathrm{I}$ via the $O$-methylation of the corresponding phenol precursor. Herein, the synthesis, in vitro characterization and radiolabeling of compounds 12 and $\mathbf{1 3}$ as well as the in vivo evaluation of $\left[{ }^{11} \mathrm{C}\right] \mathbf{1 3}$ in rats and a non-human primate are disclosed.

\section{[Figure 1]}




\section{RESULTS AND DISCUSSION}

Chemistry. Syntheses of compounds $12, \mathbf{1 3}$ and the phenolic precursor 24 are shown in Scheme $1 .^{38}$ The syntheses started from the Wittig reaction between aldehyde $\mathbf{1 4}$ and phosphorous ylide $\mathbf{1 5}$ to give compound 16. Hydrogenation of compound 16 under $40 \mathrm{psi}$ of hydrogen at room temperature led to compound $\mathbf{1 7}$, which was used in the subsequent Suzuki coupling reaction with the boronic acid species 18a-18c to furnish compounds 19a-19c. The ester groups in compounds 19a-19c were converted to tertiary alcohol moieties in compounds $20 \mathbf{a}-20 \mathbf{c}$ at $0{ }^{\circ} \mathrm{C}$ in the presence of a Grignard reagent. After cyclization of the tertiary alcohols under basic conditions, aryl chlorides 21a-21c were obtained, which were cyanated with $\mathrm{Zn}(\mathrm{CN})_{2}$ in a microwave reactor to give aryl nitriles 22a-22c. Finally, hydrolysis of 22a and 22b led to compounds $\mathbf{1 2}$ and 13, whereas compound 22c was deprotected before hydration to afford the radiolabeling precursor 24 .

During the syntheses of these compounds, several modifications were made to the previous methods. ${ }^{38}$ First, the more reactive 4-iodo-2,6-dichloronicotinaldehyde (14) instead of 4-bromo2,6-dichloronicotinaldehyde was used as starting material. Second, compound $\mathbf{1 6}$ was hydrogenated to 17 prior to the Suzuki coupling with $\mathbf{1 8 a - 1 8 c}$. Third, the carboxamide group in compounds 12, 13 and 24 was introduced by a microwave-assisted cyanation with $\mathrm{Zn}(\mathrm{CN})_{2}$ at $160{ }^{\circ} \mathrm{C}$ for 30 min followed by hydration with $\mathrm{Na}_{2} \mathrm{CO}_{3} \cdot 1.5 \mathrm{H}_{2} \mathrm{O}_{2}$. Previously, this function group was installed via the palladium-catalyzed esterification of aryl chlorides 21a-21c under 50 psi of carbon monoxide at $80{ }^{\circ} \mathrm{C}$ for $30 \mathrm{~h}$ and subsequent amidation with ammonia. The new synthetic methods in scheme 1 were robust and gave compounds 12, 13 and 24 with overall yields of $2.7 \%$, $7.1 \%$, and $1.2 \%$, respectively, whereas the yield of compound $\mathbf{1 2}$ was not disclosed previously. ${ }^{38}$

\section{[Scheme 1]}


Pharmacology and Physiochemical Properties. As previously disclosed, compound 12 had a potent mGluR2 negative allosteric modulatory activity $\left(\mathrm{IC}_{50}=6 \mathrm{nM}\right){ }^{38}$ The $\mathrm{IC}_{50}$ value was determined by measuring the inhibition of glutamate-induced calcium mobilization in Chinese Hamster Ovary $(\mathrm{CHO})$ cells expressing recombinant human mGluR2. Herein, the modulatory activity of compound $\mathbf{1 3}$ was tested by monitoring the cAMP modulation using the DiscoverX HitHunter cAMP XS+ assay. The CHO cells expressing recombinant human mGluR2 were used. Compound 13 was determined as a potent mGluR2 NAM with an $\mathrm{IC}_{50}$ value of $93.2 \mathrm{nM}$ (Fig. 2A).

Besides the mGluR2 binding, the physicochemical properties of compounds $\mathbf{1 2}$ and $\mathbf{1 3}$ were also characterized using our previously described assays. ${ }^{22}$ The assays assessed their lipophilicity, plasma stability, liver microsome stability, and their effect on recombinant human P-glycoprotein (Pgp). ${ }^{22}$ The lipophilicity of $\mathbf{1 2}$ and $\mathbf{1 3}$ was initially predicted in ChemDraw 16.0 with a cLogP value of 4.3 and 4.25 , respectively (Table 1 ). This property was further tested using the "shake flask method" to give a $\log \mathrm{D}_{7.4}$ value of 2.81 and 2.94 for compounds $\mathbf{1 2}$ and $\mathbf{1 3}$, respectively, which are in the preferred range of 1.0-3.5 for brain permeable compounds (Table 1). ${ }^{39-40}$ Compounds 12 showed excellent stabilities in rat plasma and rat liver microsome assays (> 92\%), whereas compound $\mathbf{1 3}$ had excellent rat plasma stability $(94.5 \%)$ but moderate rat liver microsome stability (47.8\%, Table 1). In addition, compounds $\mathbf{1 2}$ and $\mathbf{1 3}$ were evaluated by the Pgp-Glo ${ }^{\mathrm{TM}}$ assay. The assay detects the effects of a tested compound toward recombinant human Pgp protein in a cell membrane fraction. If the compound is a transport substrate of Pgp, it stimulates the Pgp ATPase reaction, resulting in ATP consumption and subsequent decrease of the luciferasegenerated luminescent signal. The basal Pgp ATPase activity was measured by the change in luminescence between sodium orthovanadate $\left(\mathrm{Na}_{3} \mathrm{VO}_{4}\right)$-treated controls and untreated samples. Verapamil, a known transport substrate of Pgp, was used as a positive control. As shown in Fig. 
2B and Table 1, the change in luminescence for compounds $\mathbf{1 2}$ and $\mathbf{1 3}$ was similar to that of the basal condition, suggesting neither compound $\mathbf{1 2}$ nor compound $\mathbf{1 3}$ had any effect with this protein. Therefore, compounds $\mathbf{1 2}$ and $\mathbf{1 3}$ were employed as candidates for PET imaging ligands.

To probe the ligand-protein binding of compounds $\mathbf{1 2}$ and 13, we have prepared an mGluR2 homology model for NAMs via YASARA ${ }^{41}$ and performed the molecular docking. As shown in Figs. 2C, compounds $\mathbf{1 2}$ and $\mathbf{1 3}$ adopted similar binding poses in the allosteric binding pocket. For both compounds, the oxygen atom in the carboxamide sidechain forms a hydrogen bond with Asn735 and the nitrogen atom in the carboxamide side chain forms a hydrogen bond with R636. Moreover, compound $\mathbf{1 3}$ forms an extra hydrogen bond with its methyl ether oxygen atom to Ser797 and an additional $\pi-\pi$ stacking with its phenyl ring toward Phe643. The docking score of compounds 12 and 13 were $-11.74 \mathrm{kcal} / \mathrm{mol}$ and $-11.00 \mathrm{kcal} / \mathrm{mol}$, respectively, indicating their potential nanomolar binding affinity for mGluR2.

\section{[Figure 2]}

\section{[Table 1]}

Radiochemistry. Although compound 12 had better pharmacological and physicochemical properties than compound 13, radiolabeling of this compound was challenging. As shown in scheme 2, the first attempted method utilized the palladium catalyzed cyanation of compound 21a with $\left[{ }^{11} \mathrm{C}\right] \mathrm{HCN}^{42-43}$ and subsequent amidation of $\left[{ }^{11} \mathrm{C}\right] \mathbf{2 2 a}$ with hydrogen peroxide to get $\left[{ }^{11} \mathrm{C}\right] \mathbf{1 2}$. Unfortunately, although the unlabeled compound 22a could be prepared from compound 21 a with a $71 \%$ yield at $160{ }^{\circ} \mathrm{C}$ for 30 min under the microwave conditions, $\left[{ }^{11} \mathrm{C}\right] \mathbf{2 2 a}$ was not obtained 
under the conventional heating at $160{ }^{\circ} \mathrm{C}$ for 5- or 10-min. Precursor $21 \mathrm{a}$ was intact at $180{ }^{\circ} \mathrm{C}$ for $20 \mathrm{~min}$, indicating its insufficient reactivity for such radiosynthesis. In addition, the significantly changed stoichiometry between the precursor $\mathbf{2 1 a}$ and the cyanide source might contribute to this failure considering $\left[{ }^{11} \mathrm{C}\right] \mathrm{CN}^{-}$was in the nano- or pico-molar scale. We then tried the Ru-mediated deoxyfluorination of compound $\mathbf{2 3}$ using $\left[{ }^{18} \mathrm{~F}\right]$ fluoride. ${ }^{44-45}$ However, under the typical radiofluorination conditions, $\mathbf{2 3}$ readily decomposed without forming $\left[{ }^{18} \mathrm{~F}\right] \mathbf{2 2 a}$. Alternatively, replacement of the aryl chloride in compound 21a with aryl bromide or iodide could allow the incorporation of $\left[{ }^{11} \mathrm{C}\right] \mathrm{CN}$ group due to the enhanced reactivity. Moreover, the Cu-mediated radiofluorination of the corresponding boronic acid/ester or alkyl tin precursor $\mathbf{2 5}$ may give the desired $\left[{ }^{18} \mathrm{~F}\right] \mathbf{2 2 a} .{ }^{46-47}$ This method has been successfully applied to the automated radiosynthesis of $\left[{ }^{18} \mathrm{~F}\right] \mathrm{JNJ}-46356479(\mathbf{5})$ in our group. ${ }^{48}$ On the other hand, radiolabeling of compound $\mathbf{1 3}$ was less troublesome. $\left[{ }^{11} \mathrm{C}\right] \mathbf{1 3}$ was prepared via the one-step $O$-methylation of phenol $24(1.6 \mu \mathrm{mol})$ in anhydrous dimethylformamide (DMF, $0.35 \mathrm{~mL}$ ) using $\left[{ }^{11} \mathrm{C}^{1} \mathrm{CH}_{3} \mathrm{I}\right.$ in the presence of $0.5 \mathrm{~N} \mathrm{NaOH}$ $(3.0 \mu \mathrm{L})$. The reaction was carried out at $80{ }^{\circ} \mathrm{C}$ for $3 \mathrm{~min}$, quenched by addition of $1.0 \mathrm{~mL}$ water, and purified by a semipreparative HPLC system. Noteworthy, the HPLC fractions containing $\left[{ }^{11} \mathrm{C}\right] \mathbf{1 3}$ could be trapped on a $\mathrm{C}-18$ cartridge and released via $0.6-1.0 \mathrm{~mL}$ ethanol with more than $95 \%$ recovery rate $(n=5)$. In the previous radiotracer synthesis, such as $\left[{ }^{11} \mathrm{C}\right] \mathrm{QCA}(7)$, the product was enriched by removing the HPLC solvents under reduced pressure. ${ }^{30-31,35-36}$ At the end of synthesis $(\mathrm{EOS}=45 \mathrm{~min}),\left[{ }^{11} \mathrm{C}\right] \mathbf{1 3}$ was obtained with a radiochemical yield of $42 \pm 5 \%(\mathrm{n}=5$, non-decay corrected) calculated from starting $\left[{ }^{11} \mathrm{C}\right] \mathrm{CO}_{2}$, excellent chemical and radiochemical purities $(>99 \%)$, and a high molar activity $\left(\mathrm{A}_{\mathrm{m}}\right)$ of $212 \pm 76 \mathrm{GBq} / \mu \mathrm{mol}(\mathrm{n}=5)$. As a representative 3,4-dihydro-2H-pyrano[2,3-b]pyridine NAM tracer, $\left[{ }^{11} \mathrm{C}\right] \mathbf{1 3}$ was characterized using in vivo PET imaging studies in rats and a non-human primate. 


\section{[Scheme 2]}

PET Imaging Studies in Rats. Preliminary PET imaging studies of $\left[{ }^{11} \mathrm{C}\right] 13$ were carried out in Sprague Dawley rats. Representative TACs and summed PET images at time interval of 1-30 min are shown in Fig. 3. $\left[{ }^{11} \mathrm{C}\right] \mathbf{1 3}$ showed excellent brain permeability with a maximum SUV value of 3.6 at 3 min in striatum, which was higher than that of $\left[{ }^{11} \mathrm{C}\right] \mathrm{MG}-1904\left(\mathbf{1 0}, \mathrm{SUV}_{\max }=1.7\right)^{36}$ and $\left[{ }^{11} \mathrm{C}\right] \mathrm{MG} 2-1812\left(\mathbf{1 1}, \mathrm{SUV}_{\max }=1.2\right)^{35} \cdot\left[{ }^{11} \mathrm{C}\right] \mathbf{1 3}$ had a satisfactory tracer kinetics with most of the radioactivity washed out at $30 \mathrm{~min}\left(\mathrm{SUV}_{3 \mathrm{~min}} / \mathrm{SUV}_{30 \mathrm{~min}}=2.7\right)$. Accumulation of $\left[{ }^{11} \mathrm{C}\right] 13$ was high at the mGluR2-rich regions of striatum, thalamus, cortex, hypothalamus, hippocampus, and cerebellum. $\left[{ }^{11} \mathrm{C}\right] \mathbf{1 3}$ showed improved brain heterogeneity compared to those of $\left[{ }^{11} \mathrm{C}\right] \mathrm{MG}-1904$ $(\mathbf{1 0})^{36}$ and $\left[{ }^{11} \mathrm{C}\right] \mathrm{MG} 2-1812(\mathbf{1 1})^{35}$.

The binding specificity of $\left[{ }^{11} \mathrm{C}\right] \mathbf{1 3}$ was examined by pretreatment studies with the selective mGluR2 NAM VU6001966 (9) $)^{34}$ and the potent group II NAM MNI-137 ${ }^{49}\left(\mathbf{2 6}, \mathrm{IC}_{50}=8.3 \mathrm{nM}\right)$. Pretreatment with both compounds were investigated using two different time points, namely, 1 $\min$ and $20 \mathrm{~min}$ before radioactivity. Pretreatment with $9(0.5 \mathrm{mg} / \mathrm{kg}$, iv. $) 1 \mathrm{~min}$ before tracer injection decreased the radioactivity accumulations by $22.4 \pm 7.3 \%$ across these regions of interest (ROIs) with the cortex having the highest decrease of $38.5 \%$ and thalamus the least decrease of 17.1\%. However, the blocking effect significantly decreased when this agent was administered 20 min before radioactivity, where the total average decrease was $14.5 \pm 1.5 \%$. Administration of 26 $(0.2 \mathrm{mg} / \mathrm{kg}$, iv. $) 1 \mathrm{~min}$ before $\left[{ }^{11} \mathrm{C}\right] \mathbf{1 3}$ induced a higher radioactivity decrease among these ROIs by $41.7 \pm 1.1 \%$ with the hypothalamus having the highest decrease of $42.6 \%$ and the cerebellum the least decrease of $39.6 \%$. When compound 26 was administered 20 min before $\left[{ }^{11} \mathrm{C}\right] \mathbf{1 3}$, the blocking effect significantly diminished with an average decrease of $12.7 \pm 1.7 \%$. The highest 
decrease was observed in the cerebellum (15.2\%) and the lowest decrease was seen in the striatum (11.1\%). Therefore, both compounds $\mathbf{9}$ and $\mathbf{2 6}$ showed a similar blocking pattern where the highest blocking effect occurred when these blocking agents were administered 1 min before radioactivity, whereas this blocking effect diminished with extended time gap of $20 \mathrm{~min}$. It is hypothesized the blocking agents and/or their induced pharmacological effects might wash out over time. Altogether, $\left[{ }^{11} \mathrm{C}\right] \mathbf{1 3}$ demonstrated a moderate-to-high level of specific binding toward mGluR2 in rat studies.

\section{[Figure 3]}

PET Imaging Studies in A Non-human Primate. To further characterize $\left[{ }^{11} \mathrm{C}\right] \mathbf{1 3}$ as an imaging tool for mGluR2, we performed the PET imaging studies in a cynomolgus monkey. Brain imaging in non-human primate (NHPs) is a pivotal translational approach to study the etiology of human neuropsychiatric diseases, such as schizophrenia ${ }^{5-6}$ and drug addiction ${ }^{50}$. Herein, $\left[{ }^{11} \mathrm{C}\right] \mathbf{1 3}$ was characterized for its in vivo metabolism in arterial whole-blood (WB) and plasma (PL) as well as for its binding in brain tissues by using kinetic modeling techniques. This effort will facilitate the future application of $\left[{ }^{11} \mathrm{C}\right] \mathbf{1 3}$ in humans.

Fig. 4 shows analyses of $\left[{ }^{11} \mathrm{C}\right] \mathbf{1 3}$ in arterial blood during the experimental PET imaging studies under the baseline and blocking conditions. The PL/WB ratio was similar in both studies and reached a plateau after $30 \mathrm{~min}$ of $\left[{ }^{11} \mathrm{C}\right] \mathbf{1 3}$ injection with a mean value of $1.19 \pm 0.013$. Fig. 4B shows a representative radiometabolite analysis of $\left[{ }^{11} \mathrm{C}\right] \mathbf{1 3}$ with selected plasma samples. It revealed the presence of a highly polar metabolite with a retention time $\left(t_{R}\right)$ of 2.0 min, which was likely the by-product of the $\left[{ }^{11} \mathrm{C}_{\mathrm{CH}_{3}}{ }^{-}\right.$cleaved from the phenolic methyl ether of $\left[{ }^{11} \mathrm{C}\right] 13$. Besides, there is another polar metabolite near $\left[{ }^{11} \mathrm{C}\right] \mathbf{1 3}$ with a $\mathrm{t}_{\mathrm{R}}$ of $6 \mathrm{~min}$, the structure of which was difficult 
to identify due to its extremely low amount as a tracer and its absence in neither the in vitro plasma nor microsome stability assays. We predicted the top possible sites for the metabolism of $\mathbf{1 3}$ via SMARTCyp ${ }^{51}$ where the phenolic methyl ether was ranked as the first labile group followed by the C3-C4 bond on 3,4-dihydro-2H-pyran and the pyridine nitrogen (Supporting Information, Section 5). Measurement of the percent parent (\%PP) in plasma revealed a moderate metabolism stability with $53 \pm 5.3 \%$ of radioactivity attributable to unmetabolized $\left[{ }^{11} \mathrm{C}\right] \mathbf{1 3}$ at 30 min and 24.8 $\pm 1.23 \%$ at $120 \mathrm{~min}$ (Fig. 4C). The individual metabolite-corrected $\left[{ }^{11} \mathrm{C}\right] \mathbf{1 3} \mathrm{SUV}$ time courses in plasma is shown in Fig. 4D. The plasma-free fraction $(f p)$ of $\left[{ }^{11} \mathrm{C}\right] \mathbf{1 3}$ at baseline condition $(0.131$ $\pm 0.006)$ was slightly higher than that in the blocking study $(0.099 \pm 0.011)$. The parent fraction curve of $\left[{ }^{11} \mathrm{C}\right] 13$ fitted well with a Hill function.

\section{[Figure 4]}

As shown in Fig. 5A, $\left[{ }^{11} \mathrm{C}\right] 13$ readily crossed the $\mathrm{BBB}$ and peaked at 4 min after tracer injection with a SUV value of 7.5 in the striatum in baseline condition. Selected brain regions of striatum, cerebellum non vermis, thalamus, frontal cortex and hippocampus are shown. Pharmacokinetic modeling of $\left[{ }^{11} \mathrm{C}\right] \mathbf{1 3}$ was best described by a reversible 2-tissue compartment model (2T4k1v) with a fixed vascular contribution $v$ included. According to the Akaike information criteria (AIC), ${ }^{52}$ the $2 \mathrm{~T} 4 \mathrm{k} 1 \mathrm{v}$ model provided stable regional total volume of distribution $\left(V_{T}\right)$ estimates, which symbolize the equilibrium ratio of $\left[{ }^{11} \mathrm{C}\right] \mathbf{1 3}$ in tissue to plasma as shown in Fig. 5A (left). Meanwhile, the Logan plots linearized well with $t * 30$ min and resulted in $V_{T}$ estimates that were well correlated with those derived from the $2 \mathrm{~T}$ model despite an underestimation (mean difference equals to $20 \pm 6 \%$ ) as depicted in Fig. $5 \mathrm{~A}$ (right). The high $K_{l}$ values $(0.7 \mathrm{~mL} / \mathrm{min} / \mathrm{cc})$ based on 
the $2 \mathrm{~T} 4 \mathrm{k} 1 \mathrm{v}$ model indicated high brain penetration. In the pretreatment study, compound $\mathbf{9}$ was administered $20 \mathrm{~min}$ before tracer injection at a dose of $1.0 \mathrm{mg} / \mathrm{kg}$ (iv.) considering the species and metabolic rate differences between rodents and NHPs. The $V_{T}$ estimates decreased in all ROIs over the entire acquisition. Representative Logan $V_{T}$ estimates obtained when using 120 min and $\mathrm{t}^{*}$ of 30 min are shown in Fig. 5B-C, where the decrease of $V_{T}$ estimates ranges from $16.8 \%$ in the cerebellum gray to $3.2 \%$ in the occipital gyrus with the average decrease in the whole brain as $14.1 \%$.

\section{[Figure 5]}

\section{CONCLUSION}

We have synthesized and characterized a 3,4-dihydro-2H-pyrano[2,3- $b]$ pyridine NAM 13 as a PET imaging ligand for mGluR2. Compound $\mathbf{1 3}$ has a potent negative allosteric modulatory activity and suitable physiochemical properties as a PET imaging candidate. Radiolabeling of compound 13 was achieved via the $O$-methylation of phenol 24 using $\left[{ }^{11} \mathrm{C}_{C} \mathrm{CH}_{3} \mathrm{I}\right.$ with a high radiochemical yield and a high molar activity. Preliminary PET imaging studies in rats confirmed the superior brain heterogeneity of $\left[{ }^{11} \mathrm{C}\right] \mathbf{1 3}$, particularly in striatum and cortex, as well as its favorable binding specificity and binding kinetics. Subsequent characterization of $\left[{ }^{11} \mathrm{C}\right] \mathbf{1 3}$ in a non-human primate confirmed its capability of generating high-contrast images to map the biodistribution of mGluR2 in monkey brain. Using the 2-tissue compartment model, the accumulation of $\left[{ }^{11} \mathrm{C}\right] \mathbf{1 3}$ was quantified in mGluR2-enriched brain regions, where the regional total volume of distributions $\left(V_{T}\right)$ was selectively reduced following the pretreatment of VU6001966 (9). Therefore, the experimental imaging studies conducted in two different species 
provided similar results in revealing the biological function of $\left[{ }^{11} \mathrm{C}\right] \mathbf{1 3}$. Altogether, $\left[{ }^{11} \mathrm{C}\right] 13$ is a promising PET imaging ligand for mGluR2 to be further developed for translational studies.

\section{EXPERIMENTAL SECTION}

All reagents and starting materials were obtained from the commercial sources including SigmaAldrich (St. Louis, MO), Thermo Fisher Scientific, Combi-Blocks (San Diego, CA), Ambeed (Arlington Hts, IL), and used as received. The commercially available compounds VU6001966 (9) and MNI-137 (26) were purchased from Tocris Bioscience (Minneapolis, MN). Silica gel flash column chromatography was performed using silica gel, particle size $60 \AA$, 230-400 mesh (Supelco). Microwave reactions were carried out in a CEM Discover microwave synthesizer. ${ }^{1} \mathrm{H}$ and ${ }^{13} \mathrm{C}$ nuclear magnetic resonance (NMR) spectra were collected with a JEOL $500 \mathrm{MHz}$ spectrometer using tetramethylsilane (TMS) as an internal standard. All chemical shifts $(\delta)$ are assigned as parts in per million (ppm) downfield from TMS. Signals are described as s (singlet), d (doublet), t (triplet), q (quartet), or m (multiplet). Coupling constants $(J)$ are quoted in hertz. Liquid chromatography-mass spectrometry (LCMS) was used to determine the mass and purity of all compounds $(\geq 95 \%$ ). The LCMS is equipped with a 1200 series HPLC system (Agilent Technologies, Canada), a multi-wavelength UV detector, a model 6310 ion trap mass spectrometer (Santa Clara, CA), and an analytical column (Agilent Eclipse C8, $150 \mathrm{~mm} \times 4.6 \mathrm{~mm}, 5 \mu \mathrm{m}$ ). HighResolution Mass Spectrometry (HRMS) was obtained from the Harvard Center for Mass Spectrometry at the Harvard University, Cambridge, using electrospray ionization (ESI) technique (Thermo_q-Exactive_Plus_I Mass Spectrometer).

Chemistry. Methyl (E)-3-(2,6-dichloro-4-iodopyridin-3-yl)acrylate (16). To a solution of 2,6dichloro-4-iodonicotinaldehyde $(\mathbf{1 4}, 5.0 \mathrm{~g}, 16.56 \mathrm{mmol})$ in anhydrous tetrahydrofuran $(105 \mathrm{~mL})$ 
was added methyl 2-(triphenylphosphoranylidene)acetate $(\mathbf{1 5}, 8.31 \mathrm{~g}, 24.84 \mathrm{mmol})$ under nitrogen.

The mixture was stirred at $80{ }^{\circ} \mathrm{C}$ for $2 \mathrm{~h}$. After the reaction was completed, the solvent was evaporated under vacuum and the residue was purified by silica flash column chromatography to give the product as pale-yellow solid (14.16 mmol, $5.07 \mathrm{~g}, 85.5 \%$ yield). ${ }^{1} \mathrm{H}$ NMR (500 MHz, $\left.\mathrm{CD}_{3} \mathrm{OD}\right): \delta 7.84(\mathrm{~s}, 1 \mathrm{H}), 7.54(\mathrm{~d}, J=16.3 \mathrm{~Hz}, 1 \mathrm{H}), 6.44(\mathrm{~d}, J=16.3 \mathrm{~Hz}, 1 \mathrm{H}), 3.84(\mathrm{~s}, 3 \mathrm{H}) .{ }^{13} \mathrm{C}$ NMR (125 MHz, $\left.\mathrm{CDCl}_{3}\right): \delta 165.8,149.7,147.6,141.3,133.7,133.1,128.1,112.4,52.33 . \mathrm{HRMS}$ $\left(\mathrm{ESI}^{+}\right.$) for $\mathrm{C}_{9} \mathrm{H}_{7} \mathrm{Cl}_{2} \mathrm{INO}_{2}{ }^{+}[\mathrm{M}+\mathrm{H}]^{+}$requires $\mathrm{m} / \mathrm{z}=357.8893$, found 357.8891 .

Methyl 3-(2,6-dichloro-4-iodopyridin-3-yl)propanoate (17). To a solution of $\mathbf{1 6}$ (5.5g, 15.36 $\mathrm{mmol})$ in anhydrous tetrahydrofuran /tert-Butanol $(21 \mathrm{~mL} / 21 \mathrm{~mL})$ was added the $\mathrm{RhCl}\left(\mathrm{PPh}_{3}\right)_{3}$ (2.82g, $3.05 \mathrm{mmol})$. The mixture was stirred at room temperature under $42 \mathrm{psi}_{2}$ for $48 \mathrm{~h}$. After the reaction was completed. The solvent was removed under vacuum and the residue was purified by silica flash column chromatography to give the product as white solid $\left(3.14 \mathrm{~g}, 56.8 \%\right.$ yield). ${ }^{1} \mathrm{H}$ $\operatorname{NMR}\left(500 \mathrm{MHz}, \mathrm{CDCl}_{3}\right): \delta 7.74(\mathrm{~s}, 1 \mathrm{H}), 3.72(\mathrm{~s}, 3 \mathrm{H}), 3.27(\mathrm{t}, J=8.4 \mathrm{~Hz}, 2 \mathrm{H}), 2.56(\mathrm{t}, J=8.4 \mathrm{~Hz}$, 2H). ${ }^{13} \mathrm{C} \mathrm{NMR}\left(125 \mathrm{MHz}, \mathrm{CDCl}_{3}\right): \delta 172.1,148.6,148.4,136.4,133.7,114.0,52.13,33.1,31.6$. HRMS $\left(\mathrm{ESI}^{+}\right.$) for $\mathrm{C}_{9} \mathrm{H}_{9} \mathrm{Cl}_{2} \mathrm{INO}_{2}{ }^{+}[\mathrm{M}+\mathrm{H}]^{+}$requires $\mathrm{m} / \mathrm{z}=359.9050$, found 359.9049 .

Methyl 3-(2,6-dichloro-4-(2,4-difluorophenyl)pyridin-3-yl)propanoate (19a). To a solution of 17 (0.5 g, $1.39 \mathrm{mmol})$ in 1,4-dioxane/water $(3.0 \mathrm{~mL} / 0.6 \mathrm{~mL})$ was added (2,4difluorophenyl)boronic acid (18a, $0.24 \mathrm{~g}, 1.53 \mathrm{mmol}), \mathrm{Pd}(\mathrm{dppf}) \mathrm{Cl}_{2}(0.10 \mathrm{~g}, 0.139 \mathrm{mmol})$, and $\mathrm{NaHCO}_{3}(0.234 \mathrm{~g}, 2.78 \mathrm{mmol})$. The mixture was stirred at $100{ }^{\circ} \mathrm{C}$ for $3 \mathrm{~h}$. The solvent was removed under vacuum and the residue was purified by silica flash column chromatography to give the product as a yellow oil $(0.23 \mathrm{~g}, 47.8 \%$ yield $) .{ }^{1} \mathrm{H}$ NMR $\left(500 \mathrm{MHz}, \mathrm{CDCl}_{3}\right): \delta 7.17(\mathrm{dd}, J=6.7$, $14.8 \mathrm{~Hz}, 1 \mathrm{H}), 7.12(\mathrm{~s}, 1 \mathrm{H}), 7.01(\mathrm{t}, J=8.2 \mathrm{~Hz}, 1 \mathrm{H}), 6.96(\mathrm{t}, J=9.1 \mathrm{~Hz}, 1 \mathrm{H}), 3.60(\mathrm{~s}, 3 \mathrm{H}), 2.88-$ $2.91(\mathrm{~m}, 2 \mathrm{H}), 2.48(\mathrm{t}, J=7.7 \mathrm{~Hz}, 2 \mathrm{H}) .{ }^{13} \mathrm{C} \mathrm{NMR}\left(125 \mathrm{MHz}, \mathrm{CDCl}_{3}\right): \delta 172.3,163.6(\mathrm{dd}, J=11.8$, 
$252.3 \mathrm{~Hz}), 159.0(\mathrm{dd}, J=12.1,250.5 \mathrm{~Hz}), 151.2,148.4,148.0,132.6,131.3(\mathrm{dd}, J=4.2,9.7 \mathrm{~Hz})$,

125.0, $120.9(\mathrm{~d}, J=12.5 \mathrm{~Hz}), 112.3(\mathrm{dd}, J=3.4,21.4 \mathrm{~Hz}), 104.9(\mathrm{t}, J=25.4 \mathrm{~Hz}), 51.9,32.2,25.4$.

${ }^{19} \mathrm{~F}$ NMR $\left(470 \mathrm{MHz}, \mathrm{CDCl}_{3}\right): \delta-106.99(\mathrm{dd}, J=5.9,13.0 \mathrm{~Hz}),-109.20(\mathrm{dd}, J=7.6,16.1 \mathrm{~Hz})$.

$\operatorname{HRMS}\left(\mathrm{ESI}^{+}\right.$) for $\mathrm{C}_{15} \mathrm{H}_{12} \mathrm{Cl}_{2} \mathrm{~F}_{2} \mathrm{NO}_{2}{ }^{+}[\mathrm{M}+\mathrm{H}]^{+}$requires $\mathrm{m} / \mathrm{z}=346.0208$, found 346.0208.

Methyl 3-(2,6-dichloro-4-(2-fluoro-4-methoxyphenyl)pyridin-3-yl)propanoate (19b). The

procedure described for compound 19a was applied to (2-fluoro-4-methoxyphenyl)boronic acid

(18b) to give compound $\mathbf{1 9 b}$ as a waxy pale-yellow solid $\left(0.383 \mathrm{~g}, 77.0 \%\right.$ yield). ${ }^{1} \mathrm{H}$ NMR $(500$

$\left.\mathrm{MHz}, \mathrm{CDCl}_{3}\right): \delta 7.11(\mathrm{~s}, 1 \mathrm{H}), 7.06(\mathrm{t}, J=8.5 \mathrm{~Hz}, 1 \mathrm{H}), 6.78(\mathrm{dd}, J=2.2,8.5 \mathrm{~Hz}, 1 \mathrm{H}), 6.71(\mathrm{dd}, J$ $=2.3,11.5 \mathrm{~Hz}, 1 \mathrm{H}), 3.84(\mathrm{~s}, 3 \mathrm{H}), 3.60(\mathrm{~s}, 3 \mathrm{H}), 2.92(\mathrm{t}, J=8.0 \mathrm{~Hz}, 2 \mathrm{H}), 2.47(\mathrm{t}, J=8.2 \mathrm{~Hz}, 2 \mathrm{H})$.

${ }^{13} \mathrm{C}$ NMR (125 MHz, $\left.\mathrm{CDCl}_{3}\right): \delta 172.5,161.9(\mathrm{~d}, J=10.8 \mathrm{~Hz}), 159.5(\mathrm{~d}, J=246.9 \mathrm{~Hz}), 151.0$, $149.4,147.8,132.8,130.8(\mathrm{~d}, J=4.4 \mathrm{~Hz}), 125.2,116.7(\mathrm{~d}, J=16.4 \mathrm{~Hz}), 110.8,102.1(\mathrm{~d}, J=25.3$ $\mathrm{Hz}), 55.8,51.9,32.2,25.5 .{ }^{19} \mathrm{~F} \mathrm{NMR}\left(470 \mathrm{MHz}, \mathrm{CDCl}_{3}\right): \delta-111.6(\mathrm{t}, \mathrm{J}=9.0 \mathrm{~Hz}) . \mathrm{HRMS}\left(\mathrm{ESI}^{+}\right)$ for $\mathrm{C}_{16} \mathrm{H}_{15} \mathrm{Cl}_{2} \mathrm{FNO}_{3}{ }^{+}[\mathrm{M}+\mathrm{H}]^{+}$requires $\mathrm{m} / \mathrm{z}=358.0408$, found 358.0408 .

Methyl 3-(4-(4-(benzyloxy)-2-fluorophenyl)-2,6-dichloropyridin-3-yl)propanoate (19c). The procedure described for compound 19a was applied to (4-(benzyloxy)-2-fluorophenyl)boronic acid (18c) to give compound 19c as a colorless oil $(0.46 \mathrm{~g}, 84.0 \%) .{ }^{1} \mathrm{H}$ NMR $\left(500 \mathrm{MHz}, \mathrm{CDCl}_{3}\right)$ : $\delta$ 7.40-7.44 (m, 4H), 7.34-7.37 (m, 1H), $7.12(\mathrm{~s}, 1 \mathrm{H}), 7.07(\mathrm{t}, J=8.5 \mathrm{~Hz}, 1 \mathrm{H}), 6.86(\mathrm{dd}, J=2.4$, $8.5 \mathrm{~Hz}, 1 \mathrm{H}), 6.79(\mathrm{dd}, J=2.4,11.5 \mathrm{~Hz}, 1 \mathrm{H}), 5.09(\mathrm{~s}, 2 \mathrm{H}), 3.60(\mathrm{~s}, 3 \mathrm{H}), 2.93(\mathrm{t}, J=8.2 \mathrm{~Hz}, 2 \mathrm{H})$, $2.48(\mathrm{t}, J=8.2 \mathrm{~Hz}, 2 \mathrm{H}) .{ }^{13} \mathrm{C} \mathrm{NMR}\left(125 \mathrm{MHz}, \mathrm{CDCl}_{3}\right): \delta 172.5,161.0(\mathrm{~d}, J=10.8 \mathrm{~Hz}), 159.4(\mathrm{~d}, J$ $=247.3 \mathrm{~Hz}), 151.0,149.4,147.8,136.0,132.8,130.8,128.9,128.5,127.7(\mathrm{~m}), 125.2(\mathrm{~m}), 117.0$ $(\mathrm{d}, J=16.6 \mathrm{~Hz}), 111.5,103.1(\mathrm{~d}, J=25.2 \mathrm{~Hz}), 70.6,51.9,32.3,25.5 .{ }^{19} \mathrm{~F} \mathrm{NMR}\left(470 \mathrm{MHz}, \mathrm{CDCl}_{3}\right)$ : $\delta-111.4(\mathrm{t}, \mathrm{J}=10.0 \mathrm{~Hz})$. HRMS $\left(\mathrm{ESI}^{+}\right)$for $\mathrm{C}_{22} \mathrm{H}_{19} \mathrm{Cl}_{2} \mathrm{FNO}_{3}{ }^{+}[\mathrm{M}+\mathrm{H}]^{+}$requires $\mathrm{m} / \mathrm{z}=434.0721$, found 434.0722. 
4-(2,6-dichloro-4-(2,4-difluorophenyl)pyridin-3-yl)-2-methylbutan-2-ol (20a). To a solution of 19a $(0.23 \mathrm{~g}, 0.66 \mathrm{mmol})$ in anhydrous tetrahydrofuran $(6.3 \mathrm{~mL})$ was added methylmagnesium bromide (3.0 M in diethyl ether, $1.33 \mathrm{~mL}, 4.0 \mathrm{mmol}$ ) dropwise at $0{ }^{\circ} \mathrm{C}$ under nitrogen. The mixture was stirred at $0{ }^{\circ} \mathrm{C}$ for $1 \mathrm{~h}$. After the reaction was completed, the mixture was quenched with saturated aqueous $\mathrm{NH}_{4} \mathrm{Cl}$ solution $(30 \mathrm{~mL})$ and extracted with ethyl acetate $(20 \mathrm{~mL} \times 3)$. The combined organic layers were dried over anhydrous $\mathrm{MgSO}_{4}$. The solvent was removed under reduced pressure and the residue was purified by silica flash column chromatography to give the product as a colorless oil $(0.22 \mathrm{~g}, 95.6 \%$ yield $) .{ }^{1} \mathrm{H}$ NMR $\left(500 \mathrm{MHz}, \mathrm{CDCl}_{3}\right): \delta 7.17(\mathrm{td}, J=6.3$, $8.3 \mathrm{~Hz}, 1 \mathrm{H}), 7.10(\mathrm{~s}, 1 \mathrm{H}), 6.99(\mathrm{td}, J=2.1,7.9 \mathrm{~Hz}, 1 \mathrm{H}), 6.95(\mathrm{td}, J=2.4,9.3 \mathrm{~Hz}, 1 \mathrm{H}), 2.63(\mathrm{~m}$, 2H), $1.53(\mathrm{~m}, 2 \mathrm{H}), 1.08(\mathrm{~s}, 6 \mathrm{H}), 1.03(\mathrm{~s}, 1 \mathrm{H}) .{ }^{13} \mathrm{C} \mathrm{NMR}\left(125 \mathrm{MHz}, \mathrm{CDCl}_{3}\right): \delta 163.5(\mathrm{dd}, J=11.6$ $252.1 \mathrm{~Hz}), 159.1(\mathrm{dd}, J=11.9,250.2 \mathrm{~Hz}), 151.0,148.1,147.4,134.6,131.3(\mathrm{dd}, J=4.3,9.6 \mathrm{~Hz})$, 124.8, 121.1 (dd, $J=3.8,16.6 \mathrm{~Hz}), 112.0(\mathrm{dd}, J=3.4,21.3 \mathrm{~Hz}), 104.7(\mathrm{t}, J=25.5 \mathrm{~Hz}), 70.5,42.0$, 28.8, 25.4. ${ }^{19} \mathrm{~F}$ NMR (470 MHz, $\left.\mathrm{CDCl}_{3}\right): \delta-107.27(\mathrm{~m}),-109.00(\mathrm{dd}, J=8.2,16.2 \mathrm{~Hz})$. HRMS $\left(\mathrm{ESI}^{+}\right)$for $\mathrm{C}_{16} \mathrm{H}_{16} \mathrm{Cl}_{2} \mathrm{~F}_{2} \mathrm{NO}^{+}[\mathrm{M}+\mathrm{H}]^{+}$requires $\mathrm{m} / \mathrm{z}=346.0572$, found 346.0570.

4-(2,6-dichloro-4-(2-fluoro-4-methoxyphenyl)pyridin-3-yl)-2-methylbutan-2-ol (20b). The procedure described for compound 20a was applied to $19 \mathrm{~b}$ to give compound $20 \mathrm{~b}$ as a colorless oil $\left(0.28 \mathrm{~g}, 95.2 \%\right.$ yield). ${ }^{1} \mathrm{H}$ NMR $\left(500 \mathrm{MHz} \mathrm{CDCl}_{3}\right): \delta 7.10(\mathrm{~s}, 1 \mathrm{H}), 7.07(\mathrm{t}, J=8.5 \mathrm{~Hz}, 1 \mathrm{H})$, $6.77(\mathrm{dd}, J=2.4,8.5 \mathrm{~Hz}, 1 \mathrm{H}), 6.71(\mathrm{dd}, J=2.4,11.5 \mathrm{~Hz}, 1 \mathrm{H}), 3.83(\mathrm{~s}, 3 \mathrm{H}), 2.67(\mathrm{t}, J=8.2 \mathrm{~Hz}$, 2H), $1.55(\mathrm{t}, J=8.2 \mathrm{~Hz}, 2 \mathrm{H}), 1.08(\mathrm{~s}, 6 \mathrm{H}), 1.02(\mathrm{~s}, 1 \mathrm{H}) .{ }^{13} \mathrm{C} \mathrm{NMR}\left(125 \mathrm{MHz}, \mathrm{CDCl}_{3}\right): \delta 161.8(\mathrm{~d}$, $J=10.7 \mathrm{~Hz}), 159.5(\mathrm{~d}, J=247.2 \mathrm{~Hz}), 150.8,149.1,147.2,134.8,130.8(\mathrm{~d}, J=4.1 \mathrm{~Hz}), 125.1$, $117.0(\mathrm{~d}, J=16.8 \mathrm{~Hz}), 110.5,102.0(\mathrm{~d}, J=25.2 \mathrm{~Hz}), 70.7,55.8,42.1,28.8,25.4 .{ }^{19} \mathrm{~F}$ NMR $(470$ $\left.\mathrm{MHz}, \mathrm{CDCl}_{3}\right): \delta-111.4(\mathrm{t}, J=10.1 \mathrm{~Hz})$. HRMS $\left(\mathrm{ESI}^{+}\right)$for $\mathrm{C}_{17} \mathrm{H}_{19} \mathrm{Cl}_{2} \mathrm{FNO}_{2}{ }^{+}[\mathrm{M}+\mathrm{H}]^{+}$requires $\mathrm{m} / \mathrm{z}$ $=358.0771$, found 358.0771 . 
4-(4-(4-(benzyloxy)-2-fluorophenyl)-2,6-dichloropyridin-3-yl)-2-methylbutan-2-ol (20c). The procedure described for compound 20a was applied to $19 \mathrm{c}$ to give compound 20c as a pale-yellow oil (0.37g, 92.5\%). ${ }^{1} \mathrm{H}$ NMR (500 MHz, $\left.\mathrm{CDCl}_{3}\right): \delta 7.38-7.43(\mathrm{~m}, 4 \mathrm{H}), 7.33-7.36(\mathrm{~m}, 1 \mathrm{H}), 7.10(\mathrm{~s}$, $1 \mathrm{H}), 7.07(\mathrm{t}, J=8.5 \mathrm{~Hz}, 1 \mathrm{H}), 6.85(\mathrm{dd}, J=2.4,8.5 \mathrm{~Hz}, 1 \mathrm{H}), 6.79(\mathrm{dd}, J=2.4,11.4 \mathrm{~Hz}, 1 \mathrm{H}), 5.09$ (s, 2H), 2.64-2.68 (m, 2H), 1.51-1.54 (m, 2H), $1.07(\mathrm{~s}, 6 \mathrm{H}), 1.01(\mathrm{~s}, 1 \mathrm{H}) .{ }^{13} \mathrm{C} \mathrm{NMR}(125 \mathrm{MHz}$, $\left.\mathrm{CDCl}_{3}\right): \delta 160.8(\mathrm{~d}, J=10.8 \mathrm{~Hz}), 159.4(\mathrm{~d}, J=247.2 \mathrm{~Hz}), 150.8,149.0,147.2,136.0,134.8,130.8$, $128.8(\mathrm{~m}), 128.4(\mathrm{~m}), 127.6(\mathrm{~m}), 125.2(\mathrm{~m}), 117.3(\mathrm{~d}, J=16.8 \mathrm{~Hz}), 111.3,103.0(\mathrm{~d}, J=25.4 \mathrm{~Hz})$, 70.6, 70.5, 42.1, 28.7, 25.4. ${ }^{19} \mathrm{~F} \mathrm{NMR}\left(470 \mathrm{MHz}, \mathrm{CDCl}_{3}\right): \delta-111.3(\mathrm{t}, J=10.0 \mathrm{~Hz}) . \mathrm{HRMS}\left(\mathrm{ESI}^{+}\right)$ for $\mathrm{C}_{23} \mathrm{H}_{23} \mathrm{Cl}_{2} \mathrm{FNO}_{2}{ }^{+}[\mathrm{M}+\mathrm{H}]^{+}$requires $\mathrm{m} / \mathrm{z}=434.1084$, found 434.1086 .

\section{7-chloro-5-(2,4-difluorophenyl)-2,2-dimethyl-3,4-dihydro-2H-pyrano[2,3-b]pyridine (21a).}

To a solution of $\mathbf{2 0 a}(0.22 \mathrm{~g}, 0.64 \mathrm{mmol})$ in $N, N$-dimethylacetamide $(10.0 \mathrm{~mL})$ was added cesium carbonate $(0.417 \mathrm{~g}, 1.28 \mathrm{mmol})$. The mixture was stirred at $120{ }^{\circ} \mathrm{C}$ overnight. The mixture was washed with water $(30 \mathrm{~mL})$ and extracted with ethyl acetate $(20 \mathrm{~mL}$ x 3). The combined organic layers were dried over anhydrous $\mathrm{MgSO}_{4}$. The solvent was removed under reduced pressure and the residue was purified by silica flash column chromatography to give the product as a paleyellow solid (0.068 g, 34.3\% yield). ${ }^{1} \mathrm{H} \mathrm{NMR}\left(500 \mathrm{MHz}, \mathrm{CDCl}_{3}\right): \delta 7.20(\mathrm{td}, J=6.3,8.4 \mathrm{~Hz}, 1 \mathrm{H})$, $6.97(\mathrm{ddd}, J=1.2,2.5,8.0 \mathrm{~Hz}, 1 \mathrm{H}), 6.91(\mathrm{ddd}, J=2.5,8.9,9.8 \mathrm{~Hz}, 1 \mathrm{H}), 6.79(\mathrm{~s}, 1 \mathrm{H}), 2.50(\mathrm{~m}$, 2H), $1.75(\mathrm{t}, J=6.7 \mathrm{~Hz}, 2 \mathrm{H}), 1.41(\mathrm{~s}, 6 \mathrm{H}) .{ }^{13} \mathrm{C} \mathrm{NMR}\left(125 \mathrm{MHz}, \mathrm{CDCl}_{3}\right): \delta 163.3(\mathrm{dd}, J=11.8$, 251.1 Hz), 160.4, $159.3(\mathrm{dd}, J=11.9,238.6 \mathrm{~Hz}), 147.4,147.3,131.4(\mathrm{dd}, J=4.8,9.6 \mathrm{~Hz}), 121.4$ $(\mathrm{d}, J=20.2 \mathrm{~Hz}), 117.8,113.6,111.9(\mathrm{dd}, J=3.5,21.6 \mathrm{~Hz}), 104.5(\mathrm{t}, J=25.7 \mathrm{~Hz}), 32.0,29.8,27.0$, 20.1, 20.0. ${ }^{19} \mathrm{~F}$ NMR (470 $\left.\mathrm{MHz}, \mathrm{CDCl}_{3}\right): \delta-108.44(\mathrm{~m}),-109.32(\mathrm{~m})$. HRMS (ESI ${ }^{+}$) for $\mathrm{C}_{16} \mathrm{H}_{15} \mathrm{ClF}_{2} \mathrm{NO}^{+}[\mathrm{M}+\mathrm{H}]^{+}$requires $\mathrm{m} / \mathrm{z}=310.0805$, found 310.0807 . 
7-chloro-5-(2-fluoro-4-methoxyphenyl)-2,2-dimethyl-3,4-dihydro-2H-pyrano[2,3-b]pyridine

(21b). The procedure described for compound $21 \mathbf{a}$ was applied to $\mathbf{2 0 b}$ to give compound $\mathbf{2 1 b}$ as a yellow oil (0.13 g, 48.1\% yield). ${ }^{1} \mathrm{H}$ NMR (500 MHz, $\left.\mathrm{CDCl}_{3}\right): \delta 7.09-7.13(\mathrm{~m}, 1 \mathrm{H}), 6.78(\mathrm{~s}, 1 \mathrm{H})$, 6.75-6.79 (m, 1H), $6.69(\mathrm{~d}, J=11.7 \mathrm{~Hz}, 1 \mathrm{H}), 3.83(\mathrm{~s}, 3 \mathrm{H}), 2.52-2.54(\mathrm{~m}, 2 \mathrm{H}), 1.72-1.74(\mathrm{~m}, 2 \mathrm{H})$, $1.39(\mathrm{~s}, 6 \mathrm{H}) .{ }^{13} \mathrm{C}$ NMR $\left(125 \mathrm{MHz}, \mathrm{CDCl}_{3}\right): \delta 161.6(\mathrm{~d}, J=10.9 \mathrm{~Hz}), 160.3,159.8(\mathrm{~d}, J=247.7$ $\mathrm{Hz}), 148.4,147.0,131.0(\mathrm{~d}, J=5.0 \mathrm{~Hz}), 118.0,117.4(\mathrm{~d}, J=16.7 \mathrm{~Hz}), 113.7,110.4,102.0(\mathrm{~d}, J=$ 25.6 Hz), 77.2, 55.8, 32.1, 27.0, 20.2, 20.1. ${ }^{19} \mathrm{~F} \mathrm{NMR}\left(470 \mathrm{MHz}, \mathrm{CDCl}_{3}\right): \delta$-111.4. HRMS $\left(\mathrm{ESI}^{+}\right)$ for $\mathrm{C}_{17} \mathrm{H}_{18} \mathrm{ClFNO}_{2}{ }^{+}[\mathrm{M}+\mathrm{H}]^{+}$requires $\mathrm{m} / \mathrm{z}=322.1005$, found 322.1007 .

5-(4-(benzyloxy)-2-fluorophenyl)-7-chloro-2,2-dimethyl-3,4-dihydro-2H-pyrano[2,3-

b]pyridine (21c). The procedure described for compound 21a was applied to 20c to give compound 21c as a colorless oil $(0.13 \mathrm{~g}, 40.4 \%) .{ }^{1} \mathrm{H} \mathrm{NMR}\left(500 \mathrm{MHz}, \mathrm{CDCl}_{3}\right): \delta 7.39-7.44(\mathrm{~m}, 4 \mathrm{H}), 7.34-$ $7.37(\mathrm{~m}, 1 \mathrm{H}), 7.12(\mathrm{t}, J=8.5 \mathrm{~Hz}, 1 \mathrm{H}), 6.84(\mathrm{dd}, J=2.4,8.5 \mathrm{~Hz}), 6.79(\mathrm{~s}, 1 \mathrm{H}), 6.77(\mathrm{dd}, J=2.4$, 11.7 Hz, 1H), $5.09(\mathrm{~s}, 2 \mathrm{H}), 2.54(\mathrm{t}, J=6.4 \mathrm{~Hz}, 2 \mathrm{H}), 1.74(\mathrm{t}, J=6.7 \mathrm{~Hz}, 2 \mathrm{H}), 1.41(\mathrm{~s}, 6 \mathrm{H}) .{ }^{13} \mathrm{C} \mathrm{NMR}$ $\left(125 \mathrm{MHz}, \mathrm{CDCl}_{3}\right): \delta 160.7(\mathrm{~d}, J=6.0 \mathrm{~Hz}), 160.3,159.7(\mathrm{~d}, J=231.0 \mathrm{~Hz}), 148.3,147.0,136.1$, $131.1(\mathrm{~m}), 128.8(\mathrm{~m}), 128.5(\mathrm{~m}), 127.6(\mathrm{~m}), 118.0,117.7(\mathrm{~d}, J=16.7 \mathrm{~Hz}), 113.7,111.2,102.9(\mathrm{~d}$, $J=26.6 \mathrm{~Hz}), 77.2,70.6,32.1,27.1,20.1 .{ }^{19} \mathrm{~F} \mathrm{NMR}\left(470 \mathrm{MHz}, \mathrm{CDCl}_{3}\right): \delta-111.2(\mathrm{t}, \mathrm{J}=9.2 \mathrm{~Hz})$. HRMS $\left(\mathrm{ESI}^{+}\right.$) for $\mathrm{C}_{23} \mathrm{H}_{22} \mathrm{ClFNO}_{2}{ }^{+}[\mathrm{M}+\mathrm{H}]^{+}$requires $\mathrm{m} / \mathrm{z}=398.1318$, found 398.1316.

\section{5-(2,4-difluorophenyl)-2,2-dimethyl-3,4-dihydro-2H-pyrano[2,3-b]pyridine-7-carbonitrile}

(22a). To a solution of $21 \mathrm{a}(30.0 \mathrm{mg}, 0.097 \mathrm{mmol})$ in dimethylformamide $(3.0 \mathrm{~mL})$ was added zinc cyanide $(36.0 \mathrm{mg}, 0.306 \mathrm{mmol})$ and tetrakis(triphenylphosphine)palladium(0) $(30.0 \mathrm{mg}, 0.026$ $\mathrm{mmol})$ in a microwave tube. The mixture was heated to $160^{\circ} \mathrm{C}$ in a microwave synthesizer (CEM, Discover SP) for $30 \mathrm{~min}$. The reaction was washed with water $(20 \mathrm{~mL})$ and extracted with ethyl acetate $\left(20 \mathrm{~mL}\right.$ x 3). The combined organic layers were dried over anhydrous $\mathrm{MgSO}_{4}$. The solvent 
was removed under reduced pressure and the residue was purified by silica flash column chromatography to give the product as a pale-yellow waxy solid (18.0 mg, 61.8\% yield). ${ }^{1} \mathrm{H}$ NMR $\left(500 \mathrm{MHz}, \mathrm{CDCl}_{3}\right): \delta 7.21(\mathrm{td}, J=6.3,8.4 \mathrm{~Hz}, 1 \mathrm{H}), 7.16(\mathrm{~s}, 1 \mathrm{H}), 7.02(\mathrm{td}, J=2.2,8.3 \mathrm{~Hz}, 1 \mathrm{H})$, $6.95(\mathrm{ddd}, J=2.4,8.8,9.9 \mathrm{~Hz}, 1 \mathrm{H}), 2.63(\mathrm{~m}, 2 \mathrm{H}), 1.80(\mathrm{t}, J=6.7 \mathrm{~Hz}, 2 \mathrm{H}), 1.44(\mathrm{~s}, 6 \mathrm{H}) .{ }^{13} \mathrm{C} \mathrm{NMR}$ $\left(125 \mathrm{MHz}, \mathrm{CDCl}_{3}\right): \delta 163.6(\mathrm{dd}, J=11.6,252.3 \mathrm{~Hz}), 161.5,159.3(\mathrm{dd}, J=12.0,251.0 \mathrm{~Hz}), 146.0$, $131.3(\mathrm{dd}, J=4.6,9.6 \mathrm{~Hz}), 129.9,123.2,121.0,120.6(\mathrm{~d}, J=16.3 \mathrm{~Hz}), 117.0,112.3(\mathrm{~d}, J=21.3$ $\mathrm{Hz}), 104.8(\mathrm{t}, J=25.5 \mathrm{~Hz}), 77.9,31.6,27.1,20.9,20.8 .{ }^{19} \mathrm{~F} \mathrm{NMR}\left(470 \mathrm{MHz}, \mathrm{CDCl}_{3}\right): \delta-107.32$ $(\mathrm{dd}, J=6.5,13.8 \mathrm{~Hz}),-109.04(\mathrm{dd}, J=7.4,17.4 \mathrm{~Hz})$. HRMS $\left(\mathrm{ESI}^{+}\right)$for $\mathrm{C}_{17} \mathrm{H}_{15} \mathrm{~F}_{2} \mathrm{~N}_{2} \mathrm{O}^{+}[\mathrm{M}+\mathrm{H}]^{+}$ requires $\mathrm{m} / \mathrm{z}=301.1147$, found 301.1149 .

5-(2-fluoro-4-methoxyphenyl)-2,2-dimethyl-3,4-dihydro-2H-pyrano[2,3-b]pyridine-7-

carbonitrile (22b). The procedure described for compound 22a was applied to $\mathbf{2 1 b}$ to give compound $\mathbf{2 2 b}$ as a colorless waxy solid $(18.0 \mathrm{mg}, 52.3 \%$ yield $) .{ }^{1} \mathrm{H}$ NMR $\left(500 \mathrm{MHz}, \mathrm{CDCl}_{3}\right): \delta$ $7.16(\mathrm{~s}, 1 \mathrm{H}), 7.12(\mathrm{t}, J=8.5 \mathrm{~Hz}, 1 \mathrm{H}), 6.80(\mathrm{dd}, J=2.4,8.5 \mathrm{~Hz}, 1 \mathrm{H}), 6.71(\mathrm{dd}, J=2.4,11.8 \mathrm{~Hz}$, $1 \mathrm{H}), 3.85(\mathrm{~s}, 3 \mathrm{H}), 2.67(\mathrm{t}, J=6.3 \mathrm{~Hz}, 2 \mathrm{H}), 1.78(\mathrm{t}, J=6.6 \mathrm{~Hz}, 2 \mathrm{H}), 1.43(\mathrm{~s}, 6 \mathrm{H}) .{ }^{13} \mathrm{C}$ NMR $(125$ $\left.\mathrm{MHz}, \mathrm{CDCl}_{3}\right): \delta 162.0(\mathrm{~d}, J=10.9 \mathrm{~Hz}), 161.4,159.8(\mathrm{~d}, J=248.0 \mathrm{~Hz}), 146.9,130.9(\mathrm{~d}, J=4.7$ Hz), 129.6, 123.6, 121.1, 117.2, $116.4(\mathrm{~d}, J=16.4 \mathrm{~Hz}), 110.7,102.1(\mathrm{~d}, J=25.5 \mathrm{~Hz}), 77.7,55.9$, 31.8, 27.2, 21.0. ${ }^{19} \mathrm{~F}$ NMR $\left(470 \mathrm{MHz}, \mathrm{CDCl}_{3}\right): \delta-111.1(\mathrm{t}, J=8.8 \mathrm{~Hz})$. HRMS $\left(\mathrm{ESI}^{+}\right)$for $\mathrm{C}_{18} \mathrm{H}_{18} \mathrm{FN}_{2} \mathrm{O}_{2}{ }^{+}[\mathrm{M}+\mathrm{H}]^{+}$requires $\mathrm{m} / \mathrm{z}=313.1347$, found 313.1349 .

5-(4-(benzyloxy)-2-fluorophenyl)-2,2-dimethyl-3,4-dihydro-2H-pyrano[2,3-b]pyridine-7-

carbonitrile (22c). The procedure described for compound 22a was applied to 21c to give compound $22 \mathrm{c}$ was obtained as a pale-yellow solid (29.0 mg, 29.7\%). $\left.{ }^{1} \mathrm{H} \mathrm{NMR} \mathrm{(500} \mathrm{MHz,} \mathrm{CDCl}_{3}\right)$ : ${ }^{1} \mathrm{H}$ NMR $\left(500 \mathrm{MHz}, \mathrm{CDCl}_{3}\right): \delta 7.40-7.45(\mathrm{~m}, 4 \mathrm{H}), 7.35-7.38(\mathrm{~m}, 1 \mathrm{H}), 7.17(\mathrm{~s}, 1 \mathrm{H}), 7.12(\mathrm{t}, J=8.5$ $\mathrm{Hz}, 1 \mathrm{H}), 6.87(\mathrm{dd}, J=2.4,8.5 \mathrm{~Hz}), 6.80(\mathrm{dd}, J=2.4,11.8 \mathrm{~Hz}, 1 \mathrm{H}), 5.10(\mathrm{~s}, 2 \mathrm{H}), 2.66(\mathrm{t}, J=6.6$ 
$\mathrm{Hz}, 2 \mathrm{H}), 1.79(\mathrm{t}, J=6.7 \mathrm{~Hz}, 2 \mathrm{H}), 1.44(\mathrm{~s}, 6 \mathrm{H}) .{ }^{13} \mathrm{C} \mathrm{NMR}\left(125 \mathrm{MHz}, \mathrm{CDCl}_{3}\right): \delta 161.4,161.0(\mathrm{~d}, J$ $=11.1 \mathrm{~Hz}), 159.8(\mathrm{~d}, J=248.1 \mathrm{~Hz}), 146.9,136.0,130.9(\mathrm{~d}, J=5.0 \mathrm{~Hz}), 129.6,128.9,128.5,127.6$, 123.5, 121.0, 117.2, 116.7 (d, $J=16.6 \mathrm{~Hz}), 111.5,103.1(\mathrm{~d}, J=25.5 \mathrm{~Hz}), 77.7,70.6,31.8,27.2$, 21.0. ${ }^{19} \mathrm{~F}$ NMR $\left(470 \mathrm{MHz}, \mathrm{CDCl}_{3}\right): \delta-110.9(\mathrm{t}, \mathrm{J}=9.4 \mathrm{~Hz})$. HRMS $\left(\mathrm{ESI}^{+}\right)$for $\mathrm{C}_{24} \mathrm{H}_{22} \mathrm{FN}_{2} \mathrm{O}_{2}{ }^{+}$ $[\mathrm{M}+\mathrm{H}]^{+}$requires $\mathrm{m} / \mathrm{z}=389.1660$, found 389.1656 .

\section{5-(2,4-difluorophenyl)-2,2-dimethyl-3,4-dihydro-2H-pyrano[2,3-b]pyridine-7-carboxamide}

(12). To a solution of $22 \mathrm{a}(18.0 \mathrm{mg}, 0.06 \mathrm{mmol})$ in acetone $(2.0 \mathrm{~mL})$ was added a solution of sodium percarbonate $(43.8 \mathrm{mg}, 0.29 \mathrm{mmol})$ in water $(1.0 \mathrm{~mL})$ dropwise. The mixture was stirred at room temperature for $1 \mathrm{~h}$. After the reaction was completed, the mixture was diluted with water $(20 \mathrm{~mL})$ and extracted with ethyl acetate $(20 \mathrm{~mL}$ x 3). The combined organic layers were dried over anhydrous $\mathrm{MgSO}_{4}$. The solvent was removed under reduced pressure and the residue was purified by silica flash column chromatography to give the product as a white solid (11.0 mg, $57.6 \%$ yield). ${ }^{1} \mathrm{H}$ NMR $\left(500 \mathrm{MHz}, \mathrm{CDCl}_{3}\right): \delta 7.71(\mathrm{~s}, 2 \mathrm{H}), 7.22-7.27(\mathrm{~m}, 1 \mathrm{H}), 6.99(\mathrm{td}, J=2.4,8.4 \mathrm{~Hz}$, $1 \mathrm{H}), 6.92(\mathrm{td}, J=2.4,9.4 \mathrm{~Hz}, 1 \mathrm{H}), 5.51(\mathrm{~s}, 1 \mathrm{H}), 2.60-2.64(\mathrm{~m}, 2 \mathrm{H}), 1.81(\mathrm{t}, J=6.7 \mathrm{~Hz}, 2 \mathrm{H}), 1.46$ (s, 6H). ${ }^{13} \mathrm{C}$ NMR (125 MHz, $\left.\mathrm{CDCl}_{3}\right): \delta 166.4,163.3(\mathrm{dd}, J=11.9,251.0 \mathrm{~Hz}), 159.6,159.3(\mathrm{dd}, J$ $=12.1,250.3 \mathrm{~Hz}), 146.4,146.3,131.6(\mathrm{dd}, J=4.6,9.2 \mathrm{~Hz}), 121.8(\mathrm{dd}, J=3.0,16.4 \mathrm{~Hz}), 119.3$, 117.6, $112.0(\mathrm{~d}, J=21.5 \mathrm{~Hz}), 104.4(\mathrm{t}, J=25.7 \mathrm{~Hz}), 32.0,29.8,20.8$. HRMS $\left(\mathrm{ESI}^{+}\right)$for $\mathrm{C}_{17} \mathrm{H}_{17} \mathrm{~F}_{2} \mathrm{~N}_{2} \mathrm{O}_{2}{ }^{+}[\mathrm{M}+\mathrm{H}]^{+}$requires $\mathrm{m} / \mathrm{z}=319.1253$, found 319.1253 .

5-(2-fluoro-4-methoxyphenyl)-2,2-dimethyl-3,4-dihydro-2H-pyrano[2,3-b]pyridine-7-

carboxamide (13). The procedure described for compound $\mathbf{1 2}$ was applied to $\mathbf{2 2 b}$ to give compound 13 as a white solid (25.0 mg, 78.9\% yield). ${ }^{1} \mathrm{H}$ NMR (500 MHz, $\left.\mathrm{CDCl}_{3}\right): \delta 7.73(\mathrm{~s}, 2 \mathrm{H})$, $7.18(\mathrm{t}, J=8.5 \mathrm{~Hz}, 1 \mathrm{H}), 6.79(\mathrm{dd}, J=2.3,8.5 \mathrm{~Hz}, 1 \mathrm{H}), 6.71(\mathrm{dd}, J=2.4,11.8 \mathrm{~Hz}, 1 \mathrm{H}), 5.54(\mathrm{~s}$, 1H), $3.85(\mathrm{~s}, 3 \mathrm{H}), 2.66-2.70(\mathrm{~m}, 2 \mathrm{H}), 1.81(\mathrm{t}, J=6.7 \mathrm{~Hz}, 2 \mathrm{H}), 1.47(\mathrm{~s}, 6 \mathrm{H}) .{ }^{13} \mathrm{C} \mathrm{NMR}(125 \mathrm{MHz}$, 
$\left.\mathrm{CDCl}_{3}\right): \delta 166.6,161.5(\mathrm{~d}, J=10.8 \mathrm{~Hz}), 159.6,159.8(\mathrm{~d}, J=247.5 \mathrm{~Hz}), 147.4,146.0,131.2(\mathrm{~d}, J$ $=5.2 \mathrm{~Hz}), 119.4,117.9,117.7,110.4,101.9(\mathrm{~d}, J=25.7 \mathrm{~Hz}), 77.2,55.8,32.1,27.2,20.8 .{ }^{19} \mathrm{~F} \mathrm{NMR}$ $\left(470 \mathrm{MHz}, \mathrm{CDCl}_{3}\right): \delta-111.3(\mathrm{t}, J=10.7 \mathrm{~Hz})$. HRMS $\left(\mathrm{ESI}^{+}\right)$for $\mathrm{C}_{18} \mathrm{H}_{20} \mathrm{FN}_{2} \mathrm{O}_{3}{ }^{+}[\mathrm{M}+\mathrm{H}]^{+}$requires $\mathrm{m} / \mathrm{z}=331.1452$, found 331.1454 .

5-(2-fluoro-4-hydroxyphenyl)-2,2-dimethyl-3,4-dihydro-2H-pyrano[2,3-b]pyridine-7-

carbonitrile (23). To a solution of 5-(4-(benzyloxy)-2-fluorophenyl)-2,2-dimethyl-3,4-dihydro2H-pyrano[2,3-b]pyridine-7-carbonitrile $(\mathbf{2 2 c}, 22.0 \mathrm{mg}, 0.057 \mathrm{mmol})$ in ethyl acetate $(1.3 \mathrm{~mL})$ was added palladium on carbon $(\mathrm{Pd} / \mathrm{C})(10 \mathrm{wt} . \%, 3.0 \mathrm{mg})$. The mixture was stirred at room temperature for $1 \mathrm{~h}$ under hydrogen. After the reaction was completed, $\mathrm{Pd} / \mathrm{C}$ was filtered and the solvent was removed under reduced pressure. The residue was purified by silica flash column chromatography to give the product as white solid $\left(6.0 \mathrm{mg}, 35.5 \%\right.$ yield). ${ }^{1} \mathrm{H} \mathrm{NMR}\left(500 \mathrm{MHz}, \mathrm{CDCl}_{3}\right): \delta 7.17$ (s, 1H), $7.08(\mathrm{t}, J=8.3 \mathrm{~Hz}, 1 \mathrm{H}), 6.74(\mathrm{dd}, J=2.3,8.3 \mathrm{~Hz}, 1 \mathrm{H}), 6.70(\mathrm{dd}, J=2.3,11.1 \mathrm{~Hz}, 1 \mathrm{H}), 5.52$ $(\mathrm{s}, 1 \mathrm{H}), 2.66(\mathrm{t}, J=6.8 \mathrm{~Hz}, 2 \mathrm{H}), 1.79(\mathrm{t}, J=6.7 \mathrm{~Hz}, 2 \mathrm{H}), 1.44(\mathrm{~s}, 6 \mathrm{H}) .{ }^{13} \mathrm{C} \mathrm{NMR}\left(125 \mathrm{MHz}, \mathrm{CDCl}_{3}\right)$ : $\delta 161.5,159.8(\mathrm{~d}, J=248.8 \mathrm{~Hz}), 158.2(\mathrm{~d}, J=11.9 \mathrm{~Hz}), 147.0,131.1(\mathrm{~d}, J=4.8 \mathrm{~Hz}), 129.5,123.6$, 121.2, 117.1, $116.6(\mathrm{~d}, J=16.6 \mathrm{~Hz}), 112.1,103.8(\mathrm{~d}, J=25.1 \mathrm{~Hz}), 77.8,31.8,27.1,20.9 .{ }^{19} \mathrm{~F} \mathrm{NMR}$ $\left(470 \mathrm{MHz}, \mathrm{CDCl}_{3}\right): \delta-111.2(\mathrm{t}, J=9.0 \mathrm{~Hz}) . \mathrm{HRMS}\left(\mathrm{ESI}^{+}\right)$for $\mathrm{C}_{17} \mathrm{H}_{16} \mathrm{FN}_{2} \mathrm{O}_{2}{ }^{+}[\mathrm{M}+\mathrm{H}]^{+}$requires $\mathrm{m} / \mathrm{z}$ $=299.1190$, found 299.1191.

\section{5-(2-fluoro-4-hydroxyphenyl)-2,2-dimethyl-3,4-dihydro-2H-pyrano[2,3-b]pyridine-7-}

carboxamide (24). To a solution of 5-(2-fluoro-4-hydroxyphenyl)-2,2-dimethyl-3,4-dihydro-2Hpyrano[2,3-b]pyridine-7-carbonitrile $(\mathbf{2 3}, 6.0 \mathrm{mg}, 0.02 \mathrm{mmol})$ in acetone $(0.6 \mathrm{~mL})$ was slowly added sodium bicarbonate $(9.5 \mathrm{mg}, 0.06 \mathrm{mmol})$ in water $(0.3 \mathrm{~mL})$. The resulting mixture was stirred at room temperature for $1 \mathrm{~h}$. After the reaction was completed, the reaction was quenched with saturated aqueous $\mathrm{NH}_{4} \mathrm{Cl}(1.0 \mathrm{~mL})$ and extracted with ethyl acetate $(5.0 \mathrm{~mL} \times 3)$. The 
combined organic layers were dried over anhydrous $\mathrm{MgSO}_{4}$. The solvent was removed under reduced pressure and the residue was purified by silica flash column chromatography to give the product as white solid (4.5 mg, 70.8\% yield). ${ }^{1} \mathrm{H} \mathrm{NMR}\left(500 \mathrm{MHz}, \mathrm{CDCl}_{3}\right): \delta 7.87(\mathrm{~s}, 1 \mathrm{H}), 7.64(\mathrm{~s}$, $1 \mathrm{H}), 7.39(\mathrm{~s}, 1 \mathrm{H}), 7.02(\mathrm{t}, J=8.4 \mathrm{~Hz}, 1 \mathrm{H}), 6.77(\mathrm{dd}, J=2.3,8.4 \mathrm{~Hz}, 1 \mathrm{H}), 6.70(\mathrm{dd}, J=2.3,11.4$ $\mathrm{Hz}, 1 \mathrm{H}), 5.62(\mathrm{~s}, 1 \mathrm{H}), 2.68(\mathrm{~m}, 2 \mathrm{H}), 1.80(\mathrm{t}, J=6.7 \mathrm{~Hz}, 2 \mathrm{H}), 1.46(\mathrm{~s}, 6 \mathrm{H}) .{ }^{13} \mathrm{C} \mathrm{NMR}(125 \mathrm{MHz}$, $\left.\mathrm{CDCl}_{3}\right): \delta 167.3,159.8(\mathrm{~d}, J=247.2 \mathrm{~Hz}), 159.7,158.7(\mathrm{~d}, J=11.9 \mathrm{~Hz}), 147.6,145.3,131.1(\mathrm{~d}, J$ $=5.0 \mathrm{~Hz}), 120.0,118.2,117.1(\mathrm{~d}, J=16.6 \mathrm{~Hz}), 112.1(\mathrm{~d}, J=1.9 \mathrm{~Hz}), 103.7(\mathrm{~d}, J=25.1 \mathrm{~Hz}), 32.0$, 27.2, 20.9. ${ }^{19} \mathrm{~F} \mathrm{NMR}\left(470 \mathrm{MHz}, \mathrm{CDCl}_{3}\right): \delta-111.8(\mathrm{t}, J=10.3 \mathrm{~Hz})$. HRMS $\left(\mathrm{ESI}^{+}\right)$for $\mathrm{C}_{17} \mathrm{H}_{18} \mathrm{FN}_{2} \mathrm{O}_{3}{ }^{+}$ $[\mathrm{M}+\mathrm{H}]^{+}$requires $\mathrm{m} / \mathrm{z}=317.1296$, found 317.1296.

Radiochemistry. 5-(2-fluoro-4- $\left[{ }^{11}\right.$ C]methoxyphenyl)-2,2-dimethyl-3,4-dihydro-2H-pyrano[2,3-b]pyridine-7-carboxamide $\left(\left[{ }^{11} \mathrm{C}\right] 13\right) .\left[{ }^{11} \mathrm{C}\right] \mathrm{CH}_{3} \mathrm{I}$ was prepared from the cyclotron-generated $\left[{ }^{11} \mathrm{C} \mathrm{CO}_{2}\right.$, which was produced via the ${ }^{14} \mathrm{~N}(\mathrm{p}, \alpha){ }^{11} \mathrm{C}$ reaction on nitrogen with $2.5 \%$ oxygen and 16 $\mathrm{MeV}$ protons (GE Healthcare, PETtrace). Briefly, $\left[{ }^{11} \mathrm{C}\right] \mathrm{CO}_{2}$ was trapped on molecular sieves in a TRACERlab FX-CH 3 I synthesizer (GE Healthcare) and reduced to $\left[{ }^{11} \mathrm{C}\right] \mathrm{CH}_{4}$ in the presence of hydrogen at $350{ }^{\circ} \mathrm{C}$. The resulting $\left[{ }^{11} \mathrm{C}_{\mathrm{C}} \mathrm{CH}_{4}\right.$ passed through an oven containing $\mathrm{I}_{2}$ to afford $\left[{ }^{11} \mathrm{C} \mathrm{CH}_{3} \mathrm{I}\right.$ via a radical reaction. $\left[{ }^{11} \mathrm{C}\right] \mathrm{CH}_{3} \mathrm{I}$ was then transferred under helium gas to a $5 \mathrm{~mL} \mathrm{~V}$ vial containing precursor $24(0.4 \pm 0.1 \mathrm{mg})$, an aqueous $0.5 \mathrm{~N} \mathrm{NaOH}(3 \mu \mathrm{L})$ and anhydrous DMF $(350 \mu \mathrm{L})$. After the transfer was completed, the mixture was heated at $80{ }^{\circ} \mathrm{C}$ for $3 \mathrm{~min}$. The reaction was then quenched by adding $1.0 \mathrm{~mL}$ of water and purified using a semi-preparative HPLC system equipped with a Waters XBridge C18 column $(250 \times 10 \mathrm{~mm}, 5 \mu)$, a UV detector $($ wavelength $=$ $254 \mathrm{~nm}$ ) and a radioactivity detector. The product was eluted with a mobile phase of acetonitrile/water/Et ${ }_{3} \mathrm{~N}(50 / 50 / 0.1 \%)$ at a flow rate of $5 \mathrm{~mL} / \mathrm{min}$. The fractions containing $\left[{ }^{11} \mathrm{C}\right] \mathbf{1 3}$ $\left(t_{R}=8.6 \mathrm{~min}\right)$ were collected into a large dilution flask, which was pre-loaded with $23 \mathrm{~mL}$ of sterile 
water for injection, USP. The diluted solution was loaded onto a C18 light cartridge (Waters; preactivated with $8 \mathrm{~mL}$ of EtOH followed by $16 \mathrm{~mL}$ of water) and the cartridge was washed with 10 $\mathrm{mL}$ of sterile water to remove traces of salts, residual acetonitrile and $\mathrm{Et}_{3} \mathrm{~N}$. $\left[{ }^{11} \mathrm{C}\right] \mathbf{1 3}$ was then released from the cartridge via $0.6 \mathrm{~mL}$ of dehydrated ethyl alcohol (USP) followed by $5.4 \mathrm{~mL}$ of 0.9\% sodium chloride solution (USP) into a product collection vessel. The formulated $\left[{ }^{11} \mathrm{C}\right] \mathbf{1 3}$ solution was filtered through a vented sterilizing filter (Millipore-GV 0.22 $\mu$, EMD Millipore) into a $10 \mathrm{~mL}$ vented sterile vial for injection. The synthesis time was ca. $45 \mathrm{~min}$ from end-ofbombardment. The chemical and radiochemical purities of $\left[{ }^{11} \mathrm{C}\right] \mathbf{1 3}$ were determined by a HPLC system (UltiMate 3000) equipped with an analytical column (Waters, XBridge, C18, $3.5 \mu, 4.6 \times$ $150 \mathrm{~mm})$, a UV detector $(\lambda=254 \mathrm{~nm})$ and a radioactivity detector. The mobile phase of acetonitrile/water/Et $3 \mathrm{~N}(45 / 55 / 0.1 \%)$ was used and the flow rate was $1 \mathrm{~mL} / \mathrm{min}$. The identity of $\left[{ }^{11} \mathrm{C}\right] \mathbf{1 3}$ was confirmed by the co-injection with unlabeled compound $\mathbf{1 3}$.

Pharmacology. The negative allosteric modulatory activity was determined following a standard protocol by Eurofins Discovery. Briefly, $20 \mu \mathrm{L}$ of $10 \mathrm{k}$ CHO cells/well in CP24 ${ }^{\mathrm{TM}}$ were seeded into white walled, 384-well microplates and incubated at $37^{\circ} \mathrm{C} / 5 \% \mathrm{CO}_{2}$ overnight. On day of testing, media is exchanged for $10 \mu \mathrm{L}$ of HBSS/10 mM HEPES. Intermediate dilution of compounds was performed to generate 4x stocks in HBSS/10 mM HEPES and $5 \mu \mathrm{L}$ of 4x sample is added to the cell plate. Cells were incubated at $37^{\circ} \mathrm{C}$ for 15 minutes. Then, $5 \mu \mathrm{L}$ of $4 \mathrm{x}$ Forskolin and $4 \mathrm{x} \mathrm{EC}_{80}$ of the challenge agonist glutamate were added and cells were incubated for $30 \mathrm{~min}$ at $37^{\circ} \mathrm{C}$. The concentration of Forskolin was $15 \mu \mathrm{M}$ and the concentration of glutamate was $8.9 \mu \mathrm{M}$. Assay signal was generated through incubation with $5 \mu \mathrm{L}$ of cAMP XS + Ab reagent and $20 \mu \mathrm{L}$ cAMP XS + ED/CL lysis cocktail for one hour followed by incubation with $20 \mu \mathrm{L}$ cAMP XS + EA reagent for two hours at room temperature. Plates were read following signal generation with a 
PerkinElmer Envision ${ }^{\mathrm{TM}}$ instrument for chemiluminescent signal detection. The signal is normalized to $\mathrm{EC}_{80}$ response $(0 \%)$ and basal signal (100\%). The NAM activity was analyzed using CBIS data analysis suite (ChemInnovation, CA). Percentage inhibition was calculated using the formula of $\%$ Inhibition $=100 \% \mathrm{x}$ (mean RLU of test sample-mean RLU of EC 80 control)/ (mean RLU of forskolin positive control - mean RLU of $\mathrm{EC}_{80}$ control). The assay was run in duplicate.

Molecular modeling. The mGluR2 receptor model was built in YASARA ${ }^{41}$ from 17 initial models based on the crystal structures of the human metabotropic glutamate receptor 5 (PDBID:4OO9), ${ }^{53}$ human metabotropic glutamate receptor 1 (PDBID:4OR2), ${ }^{54}$ metabotropic glutamate receptor 5 apo form (PDBID:6N52), ${ }^{55}$ and an mGluR2 structure (PDBID: 5KZN). ${ }^{56}$ The model was further validated by several structural analysis tools from SAVES containing VERIFY3D, ${ }^{57}$ ERRA, ${ }^{58}$ QMEAN,${ }^{59}$ and ModFOLD $^{60}$ (Supporting Information, Section 2). The key interacting residues were predicted by Partial Order Optimum Likelihood (POOL), ${ }^{61}$ which include the previously reported interacting residues of Phe623, Arg635, Phe643, His723, and Asn735. ${ }^{49,} 62$ Compounds $\mathbf{1 2}$ and $\mathbf{1 3}$ were optimized and converted into PDB format in Avogadro 1.2 before docking. ${ }^{63}$ Molecular docking was performed into the model structure using Extra precision Induced Fit Docking in Glide. ${ }^{64-66}$

Physiochemical Properties. Partition coefficient $\left(\log D_{7.4}\right)$. The $\log \mathrm{D}_{7.4}$ was measured by mixing a test compound $(0.1 \mathrm{mg})$ with $n$-octanol $(1.0 \mathrm{~mL})$ and PBS buffer $(1.0 \mathrm{~mL})$ at $\mathrm{pH} 7.4$ in an Eppendorf tube. ${ }^{67}$ The tube was vortexed for $1 \mathrm{~min}$ before shaken at $37{ }^{\circ} \mathrm{C}$ overnight. The amount of the test compound in each phase was determined from the area under the peak at a wavelength of $254 \mathrm{~nm}$ in the HPLC system (UltiMate 3000). The compound was eluted with acetonitrile/water/Et $3 \mathrm{~N}(45 / 55 / 0.1 \%)$ at a flow rate of $1.0 \mathrm{~mL} / \mathrm{min}$ with a Waters XBridge C18 
column $(250 \times 10 \mathrm{~mm}, 5 \mu)$. The $\log \mathrm{D}_{7.4}$ was calculated by $\log ([$ compound in octanol]/[compound in PBS]). The assay was repeated at least three times for each compound.

Rat plasma stability. The rat plasma stability was determined by our previously described method. ${ }^{22,}{ }^{68}$ Briefly, the test compound ( $2.5 \mu \mathrm{L}, 1 \mathrm{mM}$ DMSO stock solution) was mixed with an aliquot of rat serum (100 $\mu \mathrm{L}$, Abcam, Inc.) in an Eppendorf tube. The tube was vortexed and incubated at $37{ }^{\circ} \mathrm{C}$ for $0 \mathrm{~min}$ and $60 \mathrm{~min}$, separately, before the addition of $250 \mu \mathrm{L}$ ice-cold acetonitrile. The resulting mixture was centrifuged at 10, 000g for $20 \mathrm{~min}$ and the supernatant was collected for analysis on the HPLC system (UltiMate 3000). The same analytical conditions were used as those in the $\log \mathrm{D}_{7.4}$ assay. The plasma stability value was expressed as (peak area at 60 $\mathrm{min}) /($ peak area at $0 \mathrm{~min}) \mathrm{x} 100 \%$. The assay was repeated at least three times for each compound. Compound 24 was used as internal standard.

Rat liver microsome stability. The rat liver microsome stability was measured by our previously described method. ${ }^{22,69}$ Briefly, $1.5 \mu \mathrm{L}$ of $1 \mathrm{mM}$ compound solution in DMSO was added to an Eppendorf tube containing $432 \mu \mathrm{L}$ of PBS buffer. The tube was kept at $37^{\circ} \mathrm{C}$ for 10 min before a $13 \mu \mathrm{L}$ aliquot of the Sprague-Dawley rat liver microsome (Sigma-Aldrich, No. M9066) was added. The tube was vortexed before shaken at $37^{\circ} \mathrm{C}$ for $5 \mathrm{~min}$. The NADPH $(50 \mu \mathrm{L}$, $10 \mathrm{mM}$ in PBS solution) was added and the resulting mixture was incubated at $37{ }^{\circ} \mathrm{C}$ for 0 min and $60 \mathrm{~min}$, separately, before the addition of $250 \mu \mathrm{L}$ of ice-cold acetonitrile. The mixture was centrifuged at 10, 000g for 20 min and supernatant was collected for analysis on the HPLC system (UltiMate 3000). The same analytical conditions were employed as those in the $\log \mathrm{D}_{7.4}$ assay. The liver microsome stability value was expressed as (peak area at $60 \mathrm{~min}$ )/(peak area at $0 \mathrm{~min}$ ) x 100\%. The assay was repeated at least three times for each compound. Compound $\mathbf{2 4}$ was used as internal 
standard and $\mathrm{N}$-(4-chloro-3-methoxyphenyl)pyridine-2-carboxamide (ML128) was employed as positive control.

Pgp-Glo ${ }^{T M}$ assay. The Pgp-Glo ${ }^{\mathrm{TM}}$ assay was performed by following our previously described method $^{22}$ and using the manufacturer's instructions (Promega, Co. USA). Briefly, $25 \mu \mathrm{g}$ of Pgp membrane (Promega, Cat. \# V3601) was added to a 96-well plate (Thermo Lab systems, Cat. \# 9502887) containing untreated samples, $\mathrm{Na}_{3} \mathrm{VO}_{4}(100 \mu \mathrm{M})$, Verapamil $(100 \mu \mathrm{M})$, and tested compounds $(100 \mu \mathrm{M})$. The Pgp ATPase reaction was activated by adding a solution of MgATP in the assay buffer $(5 \mathrm{mM})$. After a brief mixing, the 96 -well plate was placed in a $37{ }^{\circ} \mathrm{C}$ incubator for $40 \mathrm{~min}$. The assay was then treated with $50 \mu \mathrm{L}$ ATP detection solution and incubated at room temperature for $20 \mathrm{~min}$ to develop luminescent signal. The luminescence was read on an in vivo imaging system (IVIS ${ }^{\circledR}$ Spectrum, PerkinElmer, USA). The change in luminescence relative to the $\mathrm{Na}_{3} \mathrm{VO}_{4}$ samples represents the Pgp ATPase activity with a unit of photon per second (p/s). The assay was repeated at least three times for each compound.

PET imaging studies in rats. PET imaging experiments and data analysis of $\left[{ }^{11} \mathrm{C}\right] \mathbf{1 3}$ in rats were performed by our previously described methods. ${ }^{22}$ Briefly, the imaging studies were carried out in Triumph II Preclinical Imaging System (Trifoil Imaging, LLC, Northridge, CA). Six normal Sprague Dawley rats (male, 285-421 g) were used which resulted in eight imaging studies comprising four baseline studies, two pretreatment studies with VU6001966 (9), and two blocking experiments with MNI-137 (26). For the imaging studies, rats were anesthetized with isoflurane (1.0-1.5\%) and oxygen (1-1.5 L/min) and the vital signs, such as heart rate and breathing, were monitored. The data acquisition for 60 min started from the injection of $\left[{ }^{11} \mathrm{C}\right] \mathbf{1 3}(63.0-87.3 \mathrm{MBq}$, iv.) through the tail vein using a catheter. The blocking agent $9(0.5 \mathrm{mg} / \mathrm{kg})$ was dissolved in a solution of $10 \%$ ethanol and $5 \%$ Tween-80 in $85 \%$ saline $(0.1 \mathrm{mg} / \mathrm{mL})$ while $26(0.2 \mathrm{mg} / \mathrm{kg}$, iv. $)$ 
was formulated into a solution of 10\% DMSO and 5\% Tween-20 in $85 \%$ PBS $(0.25 \mathrm{mg} / \mathrm{mL})$. The blocking agents were administered 1 or $20 \mathrm{~min}$ before the tracer injection.

After each PET acquisition, a CT scan was performed to provide anatomical information and data for attenuation correction. The list mode PET data were reconstructed to twenty-four dynamic volumetric images $(9 \times 20 \mathrm{~s}, 7 \times 1 \mathrm{~min}, 6 \times 5 \mathrm{~min}, 2 \times 10 \mathrm{~min})$ via the maximum-likelihood expectationmaximization (MLEM) algorithm with 30 iterations. The ROIs, i.e., striatum, frontal cortex, cingulate cortex, hippocampus, hypothalamus, thalamus, and cerebellum were drawn onto coronal PET slices according to the rat brain atlas. The time activity curves for these ROIs were generated by PMOD 3.2 (PMOD Technologies Ltd., Zurich, Switzerland).

PET imaging studies in a nonhuman primate. PET imaging experiments, arterial blood sampling, and data analysis of $\left[{ }^{11} \mathrm{C}\right] 13$ in a cynomolgus monkey (Macaca fascicularis) $(5.0 \mathrm{~kg}$, female) were done by our previously described methods. ${ }^{22}$

PET imaging. The PET scans were performed in a Discovery MI (GE Healthcare) PET/CT scanner. Prior to each study, the monkey was sedated with ketamine/xylazine (10/0.5 mg/kg IM) and maintained under anesthesia with a flow of isoflurane (1-2\%) in oxygen. A CT scan was done before each PET acquisition to verify anatomical location and get data for attenuation correction. The PET data acquisition started immediately at the start of a 3-minute tracer infusion and lasted for $120 \mathrm{~min}$. Radiotracer activity injected at baseline and blocking studies was $190.55 \mathrm{MBq}\left(\mathrm{A}_{\mathrm{m}}=\right.$ 288.5 GBq/ $\mu \mathrm{mol})$ and $239.39 \mathrm{MBq}\left(\mathrm{A}_{\mathrm{m}}=135.6 \mathrm{GBq} / \mu \mathrm{mol}\right)$. The blocking agent, $9(1.0 \mathrm{mg} / \mathrm{kg}$, iv.) was administered 20 min before tracer injection. After the PET scan, the acquired PET data were reconstructed via a 3D time-of-flight iterative reconstruction algorithm with 3 iterations and 34 subsets. The data were also corrected for photon attenuation and scatter, radioactive decay, system dead time, detector inhomogeneity and random coincident events. The list mode PET data 
were framed to fifty-four dynamic volumetric images $(6 \times 10,8 \times 15,6 \times 30,8 \times 60,8 \times 120$ and 18x300s) with voxel dimensions of $256 \times 256 \times 89$ and voxel sizes of $1.17 \times 1.17 \times 2.8 \mathrm{~mm}^{3}$.

Arterial blood sampling and analysis. Prior to radiotracer injection, a 3-mL arterial blood sample was drawn to determine the plasma protein binding of $\left[{ }^{11} \mathrm{C}\right] \mathbf{1 3}$. Briefly, the blood sample was centrifuged and an aliquot of the supernatant was spiked with $\left[{ }^{11} \mathrm{C}\right] 13$ in PBS to $22.2 \mathrm{MBq} / \mathrm{mL}$. The resulting solution was inculcated for 10-15 min before centrifugation with the Centrifree Ultrafiltration Devices (Millipore Sigma). Aliquots of the ultrafiltrate $\left(\mathrm{C}_{\text {free }}\right)$ and the plasma mixture $\left(\mathrm{C}_{\text {total }}\right)$ were measured for radioactive concentration in a Wallac Wizard 2480 gamma counter. This process was performed in triplicate to determine the plasma free fraction $\left(f_{p}\right)$ of $\left[{ }^{11} \mathrm{C}\right] 13$.

Upon PET data acquisition, twenty three arterial blood samples were drawn by sampling every 30 seconds for the first 5 minutes followed by a decreased frequency of every 15 minutes till the end of the scan. The plasma samples were obtained as supernatant of the centrifugated wholeblood samples. The metabolism of $\left[{ }^{11} \mathrm{C}\right] \mathbf{1 3}$ was evaluated using selected plasma samples from 5 , $10,15,30,60,90$, and 120 minutes. The amount of the intact $\left[{ }^{11} \mathrm{C}\right] \mathbf{1 3}$ in plasma samples were measured by the previously described automated column switching radioHPLC system. ${ }^{70-71}$ Briefly, the plasma sample was trapped on a capture column (Waters Oasis HLB $30 \mu \mathrm{m}$ ) with a mobile phase of water: acetonitrile (99:1) at $1.8 \mathrm{~mL} / \mathrm{min}$ (Waters 515 pump). After 4 minutes, the sample was transferred to an analytical column (Waters XBridge BEH C18, $130 \AA$ A, $3.5 \mu \mathrm{m}, 4.6$ $\mathrm{mm} \times 100 \mathrm{~mm}$ ) by backflushing the catch column with a mobile phase of acetonitrile: $0.1 \mathrm{M}$ ammonium formate in water (45:55) at $1 \mathrm{~mL} / \mathrm{min}$ (Waters 515 pump) with $0.1 \%$ of TFA (pH 2.5). The eluent from the analytical column was collected in 1-minute intervals and the radioactivity was measured to determine the parent fraction in plasma (\%PP) with a Wallac Wizard 2480 gamma 
counter. The radioactivity concentration $(\mathrm{C}(\mathrm{t}))$ measured from the well counter was expressed as $\mathrm{kBq} / \mathrm{cc}$. Therefore, the radioactivity time courses using standardized uptake value (SUV) was calculated as $\mathrm{SUV}(\mathrm{t})=\mathrm{C}(\mathrm{t}) /(\mathrm{ID} / \mathrm{BW})$, where ID standards for injected dose in MBq and BW means body weight in $\mathrm{kg}$. The time courses of $\% \mathrm{PP}(\mathrm{t})$ were fitted with a sum of two decaying exponentials plus a constant. The resulting model fit and the $\left(\mathrm{C}_{\text {total }}(\mathrm{t})\right)$ in plasma were multiplied to derive the metabolite-corrected arterial input function for kinetic modeling. ${ }^{24,72}$

Image processing and analyses. All PET data were processed with an in-house developed MATLAB software that uses FSL. ${ }^{73}$ The PET images were first co-registered to the structural T1weighted magnetization-prepared rapid gradient-echo (MEMPRAGE) images, which were aligned into an (magnetic resonance) MR monkey template space. ${ }^{74}$ The resulting transformation was then applied to PET images. Regional TACs were extracted from the native PET image space for specific ROIs.

The extracted TACs were modeled via the reversible one- (1T) and two- (2T) tissue compartment model configurations with the metabolite-corrected arterial plasma input function. The 2T model was assessed in its irreversible $\left(\mathrm{k}_{4}=0\right)$ and reversible configurations. A fixed vascular contribution of the WB radioactivity to the PET signal was set to $5 \%$. The kinetic parameters were estimated using the nonlinear weighted least-squares fitting and the frame durations were chosen for the weights. Regional total volume of distributions $\left(V_{T}\right)$ were calculated from the estimated microparameters following the consensus nomenclature reported by Innis et $a l .^{75}$ The stability of $V_{T}$ estimates was assessed by progressively truncating the PET data in 10 min increment from the full duration of $120 \mathrm{~min}$ to $60 \mathrm{~min}$. Additionally, the Logan graphical analysis technique was also assessed to generate $V_{T}$ estimates with different cutoff time ${ }^{*}{ }^{76}$ 


\section{ASSOCIATED CONTENT}

\section{Supporting Information}

The Supporting Information is available free of charge on the ACS Publications website at DOI:

Molecular formular strings (CSV)

Preparation and validation of mGluR2 NAM model, POOL prediction of key residues, semipreparative HPLC purification and analytical HPLC characterization of $\left[{ }^{11} \mathrm{C}\right] \mathbf{1 3}$, and ${ }^{1} \mathrm{H},{ }^{13} \mathrm{C}$ NMR spectra for synthesized compounds (PDF)

The PDB coordinates of the mGluR2 NAM model (PDB)

\section{AUTHOR INFORMATION}

\section{Corresponding Authors}

*G.Y.: phone 857-210-6386; email, gyyuan@mgh.harvard.edu; ORCID ID:

https://orcid.org/0000-0003-4817-0052

*A-L.B.: phone 617-744-3725; email, abrownell@mgh.harvard.edu; ORCID ID:

https://orcid.org/0000-0002-3814-868X

\section{Author Contributions}

The manuscript was written through contributions of all authors.

\section{Notes}

The authors declare no conflict interest.

\section{ACKNOWLEDGEMENT}

This project was funded by NIH grants [R01EB021708, R01NS100164, 1S10RR023452-01 and 1S10OD025234-01] for the imaging instrumentation and characterization of the organic 
compounds. This projected was supported by the NIH grants [S10OD018035 and P41EB022544] for the blood counting and metabolite analysis equipment.

\section{ABBREVIATIONS USED}

CNS, central nervous system; mGluR2, metabotropic glutamate receptor 2; PET, positron emission tomography; PAM, positive allosteric modulator; NAM, negative allosteric modulator; BBB, blood-brain barrier; 7-TM, seven transmembrane; Pgp-BCRP, P-glycoprotein and the breast cancer resistance protein, P-glycoprotein; $\mathrm{CHO}$, chinese hamster ovary; DMF, dimethylformamide; DMA, dimethylacetamide; EOS, end of synthesis; LCMS, Liquid chromatography-mass spectrometry; NHP, non-human primate; ROI, region of interest; TAC, time-activity curve; $f_{p}$, plasma free fraction; WB, whole-blood; PL, plasma; AIC, Akaike information criteria; NMT, NIMH macaque template; SUV, standardized uptake value; $V_{T}$, regional total volume of distribution; MEMPRAGE, magnetization-prepared rapid gradient-echo; USP, United States Pharmacopeia; MLEM, maximum-likelihood expectation-maximization. 


\section{References}

(1) Watkins, J. C. l-glutamate as a central neurotransmitter: looking back. Biochem. Soc. Trans. 2000, 28, 297-309.

(2) Nakanishi, S. Molecular diversity of glutamate receptors and implications for brain function. Science. 1992, 258, 597-603.

(3) Kew, J. N.; Kemp, J. A. Ionotropic and metabotropic glutamate receptor structure and pharmacology. Psychopharmacology (Berl). 2005, 179, 4-29.

(4) Niswender, C. M.; Conn, P. J. Metabotropic glutamate receptors: physiology, pharmacology, and disease. Annu. Rev. Pharmacol. Toxicol. 2010, 50, 295-322.

(5) Chaki, S. Group II metabotropic glutamate receptor agonists as a potential drug for schizophrenia. Eur. J. Pharmacol. 2010, 639, 59-66.

(6) Downing, A. M.; Kinon, B. J.; Millen, B. A.; Zhang, L.; Liu, L.; Morozova, M. A.; Brenner, R.; Rayle, T. J.; Nisenbaum, L.; Zhao, F.; Gomez, J. C. A double-blind, placebo-controlled comparator study of LY2140023 monohydrate in patients with schizophrenia. BMC Psychiatry 2014, $14,351$.

(7) Conn, P. J.; Jones, C. K. Promise of mGluR2/3 activators in psychiatry. Neuropsychopharmacology. 2009, 34, 248-249.

(8) Muguruza, C.; Meana, J. J.; Callado, L. F. Group II metabotropic glutamate receptors as targets for novel antipsychotic drugs. Front. Pharmacol. 2016, 7, 130.

(9) Feyissa, A. M.; Woolverton, W. L.; Miguel-Hidalgo, J. J.; Wang, Z.; Kyle, P. B.; Hasler, G.; Stockmeier, C. A.; Iyo, A. H.; Karolewicz, B. Elevated level of metabotropic glutamate receptor 2/3 in the prefrontal cortex in major depression. Prog. Neuropsychopharmacol. Biol. Psychiatry. 2010, 34, 279-283. 
(10) Mazzitelli, M.; Palazzo, E.; Maione, S.; Neugebauer, V. Group II metabotropic glutamate receptors: role in pain mechanisms and pain modulation. Front. Mol. Neurosci. 2018, 11, 383.

(11) Richards, G.; Messer, J.; Faull, R. L.; Stadler, H.; Wichmann, J.; Huguenin, P.; Bohrmann, B.; Mutel, V. Altered distribution of mGlu2 receptors in beta-amyloid-affected brain regions of Alzheimer cases and aged PS2APP mice. Brain Res. 2010, 1363, 180-190.

(12) Cartmell, J.; Schoepp, D. D. Regulation of neurotransmitter release by metabotropic glutamate receptors. J. Neurochem. 2000, 75, 889-907.

(13) Adams, D. H.; Kinon, B. J.; Baygani, S.; Millen, B. A.; Velona, I.; Kollack-Walker, S.; Walling, D. P. A long-term, phase 2, multicenter, randomized, open-label, comparative safety study of pomaglumetad methionil (LY2140023 monohydrate) versus atypical antipsychotic standard of care in patients with schizophrenia. BMC Psychiatry. 2013, 13, 143.

(14) Stauffer, V. L.; Millen, B. A.; Andersen, S.; Kinon, B. J.; Lagrandeur, L.; Lindenmayer, J. P.; Gomez, J. C. Pomaglumetad methionil: No significant difference as an adjunctive treatment for patients with prominent negative symptoms of schizophrenia compared to placebo. Schizophr. Res. 2013, $150,434-441$.

(15) Fell, M. J.; Svensson, K. A.; Johnson, B. G.; Schoepp, D. D. Evidence for the role of metabotropic glutamate $(\mathrm{mGlu}) 2$ not mGlu3 receptors in the preclinical antipsychotic pharmacology of the mGlu2/3 receptor agonist (-)-(1R,4S,5S,6S)-4-amino-2sulfonylbicyclo[3.1.0]hexane-4,6-dicarboxylic acid (LY404039). J. Pharmacol. Exp. Ther. 2008, 326, 209-217.

(16) Woolley, M. L.; Pemberton, D. J.; Bate, S.; Corti, C.; Jones, D. N. C. The mGlu2 but not the mGlu3 receptor mediates the actions of the mGluR2/3 agonist, LY379268, in mouse models predictive of antipsychotic activity. Psychopharmacology (Berl). 2008, 196 (3), 431-440. 
(17) Conn, P. J.; Christopoulos, A.; Lindsley, C. W. Allosteric modulators of GPCRs: a novel approach for the treatment of CNS disorders. Nat. Rev. Drug Discov. 2009, 8, 41-54.

(18) Sheffler, D. J.; Pinkerton, A. B.; Dahl, R.; Markou, A.; Cosford, N. D. Recent progress in the synthesis and characterization of group II metabotropic glutamate receptor allosteric modulators. ACS Chem. Neurosci. 2011, 2, 382-393.

(19) Yu, M.; Nagren, K.; Chen, Y. I.; Livni, E.; Elmaleh, D.; Kozikowski, A.; Wang, X.; Jokivarsi, K.; Brownell, A. L. Radiolabeling and biodistribution of methyl 2-(methoxycarbonyl)-2(methylamino) bicyclo[2.1.1] -hexane -5-carboxylate, a potential neuroprotective drug. Life Sci. 2003, 73, 1577-1585.

(20) Wang, J. Q.; Zhang, Z.; Kuruppu, D.; Brownell, A. L. Radiosynthesis of PET radiotracer as a prodrug for imaging group II metabotropic glutamate receptors in vivo. Bioorg. Med. Chem. Lett. 2012, 22, 1958-1962.

(21) Leurquin-Sterk, G.; Celen, S.; Van Laere, K.; Koole, M.; Bormans, G.; Langlois, X.; Van Hecken, A.; Te Riele, P.; Alcazar, J.; Verbruggen, A.; de Hoon, J.; Andres, J. I.; Schmidt, M. E. What we observe in vivo is not always what we see in vitro: development and validation of $11 \mathrm{C}$ JNJ-42491293, a novel radioligand for mGluR2. J. Nucl. Med. 2017, 58, 110-116.

(22) Yuan, G.; Qu, X.; Zheng, B.; Neelamegam, R.; Afshar, S.; Iyengar, S.; Pan, C.; Wang, J.; Kang, H. J.; Ondrechen, M. J.; Poutiainen, P.; El Fakhri, G.; Zhang, Z.; Brownell, A. L. Design, synthesis, and characterization of benzimidazole derivatives as positron emission tomography imaging ligands for metabotropic glutamate receptor 2. J. Med. Chem. 2020, 63, 12060-12072.

(23) Yuan, G.; Dhaynaut, M.; Guehl, N. J.; Neelamegam, R.; Moon, S. H.; Qu, X.; Poutiainen, P.; Afshar, S.; El Fakhri, G.; Brownell, A. L.; Normandin, M. D. PET imaging studies to investigate 
functional expression of mGluR2 using $\left[{ }^{11} \mathrm{C}\right] \mathrm{mG} 2 \mathrm{P} 001$. J. Cereb. Blood Flow Metab. 2021, Submitted.

(24) Yuan, G.; Guehl, N. J.; Zheng, B.; Qu, X.; Moon, S. H.; Dhaynaut, M.; Shoup, T. M.; Afshar, S.; Kang, H. J.; Zhang, Z.; El Fakhri, G.; Normandin, M. D.; Brownell, A. L. Synthesis and characterization of $\left[{ }^{18} \mathrm{~F}\right] \mathrm{JNJ}-46356479$ as the first ${ }^{18} \mathrm{~F}$-labeled PET imaging ligand for metabotropic glutamate receptor 2. Mol. Imaging. Biol. 2021.

(25) Yuan, G.; Dhaynaut, M.; Guehl, N.; Afshar, S.; Huynh, D.; Moon, S.-H.; Iyengar, S.; Kang, H. J.; Ondrechen, M. J.; El Fakhri, G.; Normandin, M. D.; Brownell, A. L. Design, synthesis and characterization of $\left[{ }^{18} \mathrm{~F}\right] \mathrm{mG} 2 \mathrm{P} 026$ as a high contrast PET imaging ligand for metabotropic glutamate receptor 2. J. Med. Chem. 2021, Submitted.

(26) O'Brien, D. E.; Shaw, D. M.; Cho, H. P.; Cross, A. J.; Wesolowski, S. S.; Felts, A. S.; Bergare, J.; Elmore, C. S.; Lindsley, C. W.; Niswender, C. M.;Conn, P. J. Differential pharmacology and binding of mGlu2 receptor allosteric modulators. Mol. Pharmacol. 2018, 93, 526-540.

(27) Doornbos, M. L. J.; Perez-Benito, L.; Tresadern, G.; Mulder-Krieger, T.; Biesmans, I.; Trabanco, A. A.; Cid, J. M.; Lavreysen, H.; IJzerman, A. P.; Heitman, L. H. Molecular mechanism of positive allosteric modulation of the metabotropic glutamate receptor 2 by JNJ-46281222. $\mathrm{Br}$. J. Pharmacol. 2016, 173, 588-600.

(28) Lavreysen, H.; Langlois, X.; Ahnaou, A.; Drinkenburg, W.; te Riele, P.; Biesmans, I.; Van der Linden, I.; Peeters, L.; Megens, A.; Wintmolders, C.; Cid, J. M.; Trabanco, A. A.; Andres, J. I.; Dautzenberg, F. M.; Lutjens, R.; Macdonald, G.; Atack, J. R. Pharmacological characterization of JNJ-40068782, a new potent, selective, and systemically active positive allosteric modulator of the mGlu2 receptor and its radioligand $\left[{ }^{3} \mathrm{H}\right] \mathrm{JNJ}-40068782$. J. Pharmacol. Exp. Ther. 2013, 346, 514-527. 
(29) Lundstrom, L.; Bissantz, C.; Beck, J.; Wettstein, J. G.; Woltering, T. J.; Wichmann, J.; Gatti,

S. Structural determinants of allosteric antagonism at metabotropic glutamate receptor 2: mechanistic studies with new potent negative allosteric modulators. Br. J. Pharmacol. 2011, 164, $521-537$.

(30) Zhang, X.; Kumata, K.; Yamasaki, T.; Cheng, R.; Hatori, A.; Ma, L.; Zhang, Y.; Xie, L.; Wang, L.; Kang, H. J.; Sheffler, D. J.; Cosford, N. D. P.; Zhang, M. R.; Liang, S. H. Synthesis and preliminary studies of a novel negative allosteric modulator, 7-((2,5-dioxopyrrolidin-1-yl)methyl)4-(2-fluoro-4-[ $\left.{ }^{11} \mathrm{C}\right]$ methoxyphenyl) quinoline-2-carboxamide, for imaging of metabotropic glutamate receptor 2. ACS Chem. Neurosci. 2017, 8, 1937-1948.

(31) Kumata, K.; Hatori, A.; Yamasaki, T.; Zhang, Y.; Mori, W.; Fujinaga, M.; Xie, L.; Nengaki, N.; Zhang, M. R. Synthesis and evaluation of 4-(2-fluoro-4-[ $\left[{ }^{11} \mathrm{C}\right]$ methoxyphenyl)-5-((2methylpyridin-4-yl)methoxy)picolinamide for PET imaging of the metabotropic glutamate receptor 2 in the rat brain. Bioorg. Med. Chem. 2019, 27, 483-491.

(32) Bungard, C. J.; Converso, A.; de Leon, P.; Hanney, B.; Hartingh, T. J.; Manikowski, J. J.; Manley, P. J.; Meissner, R.; Meng, Z.; Perkins, J. J.; Rudd, M. T.; Shu, Y. Quinoline carboxamide and quinoline carbonitrile derivatives as mGluR2-negative allosteric modulators, compositions, and their use. Patent WO2013066736, October 5, 2013.

(33) Felts, A. S.; Rodriguez, A. L.; Smith, K. A.; Engers, J. L.; Morrison, R. D.; Byers, F. W.; Blobaum, A. L.; Locuson, C. W.; Chang, S.; Venable, D. F.; Niswender, C. M.; Daniels, J. S.; Conn, P. J.; Lindsley, C. W.; Emmitte, K. A. Design of 4-oxo-1-aryl-1,4-dihydroquinoline-3carboxamides as selective negative allosteric modulators of metabotropic glutamate receptor subtype 2. J. Med. Chem. 2015, 58, 9027-9040. 
(34) Bollinger, K. A.; Felts, A. S.; Brassard, C. J.; Engers, J. L.; Rodriguez, A. L.; Weiner, R. L.; Cho, H. P.; Chang, S.; Bubser, M.; Jones, C. K.; Blobaum, A. L.; Niswender, C. M.; Conn, P. J.; Emmitte, K. A.; Lindsley, C. W. Design and synthesis of mGlu2 NAMs with improved potency and CNS penetration based on a truncated picolinamide Core. ACS. Med. Chem. Lett. 2017, 8, 919-924.

(35) Yamasaki, T.; Zhang, X.; Kumata, K.; Zhang, Y.; Deng, X.; Fujinaga, M.; Chen, Z.; Mori, W.; Hu, K.; Wakizaka, H.; Hatori, A.; Xie, L.; Ogawa, M.; Nengaki, N.; Van, R.; Shao, Y.; Sheffler, D. J.; Cosford, N. D. P.; Liang, S. H.; Zhang, M. R. Identification and development of a new positron emission tomography ligand 4-(2-fluoro-4-[ $\left.{ }^{11} \mathrm{C}\right]$ methoxyphenyl)-5-((1-methyl-1Hpyrazol-3-yl)methoxy)picolinamide for imaging metabotropic glutamate receptor subtype 2 (mGlu2). J. Med. Chem. 2020, 63, 11469-11483.

(36) Zhang, X.; Zhang, Y.; Chen, Z.; Shao, T.; Van, R.; Kumata, K.; Deng, X.; Fu, H.; Yamasaki, T.; Rong, J.; Hu, K.; Hatori, A.; Xie, L.; Yu, Q.; Ye, W.; Xu, H.; Sheffler, D. J.; Cosford, N. D. P.; Shao, Y.; Tang, P.; Wang, L.; Zhang, M. R.; Liang, S. H. Synthesis and preliminary studies of ${ }^{11}$ C-labeled tetrahydro-1,7-naphthyridine-2-carboxamides for PET imaging of metabotropic glutamate receptor 2. Theranostics. 2020, 10, 11178-11196.

(37) Arasappan, A.; Bungard, C. J.; Fire, J. L.; Han, Y.; Hoyt, S. B.; Manley, P. J.; Meissner, R. S.; Perkins, J. J.; Sebhat, I. K.; Wilkening, R. R.; Leavitt, K. J. Tetrahydronaphthyridine derivatives as mGluR2-negative allosteric modulators. Patent WO2016032921, March 3, 2016.

(38) Sebhat, I. K.; Arasappan, A.; Hoyt, S. B.; Wilkening, R. R.; Demong, D. Chromane, isochromane and dihydroisobenzofuran derivatives as mGluR2-negative allosteric modulators, compositions, and their use. Patent WO2018063955, May 04, 2018. 
(39) Pike, V. W. Considerations in the development of reversibly binding PET Radioligands for brain imaging. Curr. Med. Chem. 2016, 23, 1818-1869.

(40) Waterhouse, R. N. Determination of lipophilicity and its use as a predictor of blood-brain barrier penetration of molecular imaging agents. Mol. Imaging Biol. 2003, 5, 376-389.

(41) Krieger, E.; Joo, K.; Lee, J.; Lee, J.; Raman, S.; Thompson, J.; Tyka, M.; Baker, D.; Karplus, K. Improving physical realism, stereochemistry, and side-chain accuracy in homology modeling: Four approaches that performed well in CASP8. Proteins. 2009, 77, 114-122.

(42) Zhao, W.; Lee, H. G.; Buchwald, S. L.; Hooker, J. M. Direct ${ }^{11}$ CN-labeling of unprotected peptides via palladium-mediated sequential cross-coupling reactions. J. Am. Chem. Soc. 2017, 139, $7152-7155$.

(43) Lee, H. G.; Milner, P. J.; Placzek, M. S.; Buchwald, S. L.; Hooker, J. M. Virtually instantaneous, room-temperature $\left[{ }^{11} \mathrm{C}\right]$-cyanation using biaryl phosphine $\mathrm{Pd}(0)$ complexes. $J . A m$. Chem. Soc. 2015, 137, 648-651.

(44) Strebl, M. G.; Campbell, A. J.; Zhao, W. N.; Schroeder, F. A.; Riley, M. M.; Chindavong, P. S.; Morin, T. M.; Haggarty, S. J.; Wagner, F. F.; Ritter, T.; Hooker, J. M. HDAC6 brain mapping with $\left[{ }^{18} \mathrm{~F}\right]$ Bavarostat enabled by a Ru-mediated deoxyfluorination. ACS Cent. Sci. 2017, 3, 10061014.

(45) Beyzavi, M. H.; Mandal, D.; Strebl, M. G.; Neumann, C. N.; D'Amato, E. M.; Chen, J.; Hooker, J. M.; Ritter, T. ${ }^{18}$ F-Deoxyfluorination of Phenols via Ru pi-Complexes. ACS Cent. Sci. 2017, 3, 944-948.

(46) Preshlock, S.; Calderwood, S.; Verhoog, S.; Tredwell, M.; Huiban, M.; Hienzsch, A.; Gruber, S.; Wilson, T. C.; Taylor, N. J.; Cailly, T.; Schedler, M.; Collier, T. L.; Passchier, J.; Smits, R.; Mollitor, J.; Hoepping, A.; Mueller, M.; Genicot, C.; Mercier, J.; Gouverneur, V. Enhanced 
copper-mediated ${ }^{18} \mathrm{~F}$-fluorination of aryl boronic esters provides eight radiotracers for PET applications. Chem. Commun. (Camb) 2016, 52, 8361-8364.

(47) Taylor, N. J.; Emer, E.; Preshlock, S.; Schedler, M.; Tredwell, M.; Verhoog, S.; Mercier, J.; Genicot, C.; Gouverneur, V. Derisking the $\mathrm{Cu}$-mediated ${ }^{18} \mathrm{~F}$-fluorination of heterocyclic positron emission tomography radioligands. J. Am. Chem. Soc. 2017, 139, 8267-8276.

(48) Yuan, G.; Shoup, T. M.; Moon, S. H.; Brownell, A. L. A concise method for fully automated radiosyntheses of $\left[{ }^{18} \mathrm{~F}\right] \mathrm{JNJ}-46356479$ and $\left[{ }^{18} \mathrm{~F}\right] \mathrm{FITM}$ via $\mathrm{Cu}$-mediated ${ }^{18} \mathrm{~F}$-fluorination of organoboranes. RSC. Adv. 2020, 10, 25223-25227.

(49) Hemstapat, K.; Da Costa, H.; Nong, Y.; Brady, A. E.; Luo, Q.; Niswender, C. M.; Tamagnan, G. D.; Conn, P. J. A novel family of potent negative allosteric modulators of group II metabotropic glutamate receptors. J. Pharmacol. Exp. Ther. 2007, 322, 254-264.

(50) Nader, M. A.; Czoty, P. W. Brain imaging in nonhuman primates: insights into drug addiction. ILAR J. 2008, 49, 89-102.

(51) Rydberg, P.; Gloriam, D. E.; Zaretzki, J.; Breneman, C.; Olsen, L. SMARTCyp: A 2D method for prediction of cytochrome P450-mediated drug metabolism. ACS Med. Chem. Lett. 2010, 1, 96100.

(52) Akaike, H. A new look at the statistical model identification. IEEE Trans. Automat. Contr. 1974, 19, 716-723.

(53) Dore, A. S.; Okrasa, K.; Patel, J. C.; Serrano-Vega, M.; Bennett, K.; Cooke, R. M.; Errey, J. C.; Jazayeri, A.; Khan, S.; Tehan, B.; Weir, M.; Wiggin, G. R.; Marshall, F. H. Structure of class C GPCR metabotropic glutamate receptor 5 transmembrane domain. Nature. 2014, 511, 557-562. 
(54) Wu, H.; Wang, C.; Gregory, K. J.; Han, G. W.; Cho, H. P.; Xia, Y.; Niswender, C. M.; Katritch, V.; Meiler, J.; Cherezov, V.; Conn, P. J.; Stevens, R. C. Structure of a class C GPCR metabotropic glutamate receptor 1 bound to an allosteric modulator. Science. 2014, 344, 58-64.

(55) Koehl, A.; Hu, H.; Feng, D.; Sun, B.; Zhang, Y.; Robertson, M. J.; Chu, M.; Kobilka, T. S.; Laeremans, T.; Steyaert, J.; Tarrasch, J.; Dutta, S.; Fonseca, R.; Weis, W. I.; Mathiesen, J. M.; Skiniotis, G.; Kobilka, B. K. Structural insights into the activation of metabotropic glutamate receptors. Nature. 2019, 566, 79-84.

(56) Chappell, M. D.; Li, R.; Smith, S. C.; Dressman, B. A.; Tromiczak, E. G.; Tripp, A. E.; Blanco, M. J.; Vetman, T.; Quimby, S. J.; Matt, J.; Britton, T. C.; Fivush, A. M.; Schkeryantz, J. M.; Mayhugh, D.; Erickson, J. A.; Bures, M. G.; Jaramillo, C.; Carpintero, M.; Diego, J. E.; Barberis, M.; Garcia-Cerrada, S.; Soriano, J. F.; Antonysamy, S.; Atwell, S.; MacEwan, I.; Condon, B.; Sougias, C.; Wang, J.; Zhang, A.; Conners, K.; Groshong, C.; Wasserman, S. R.; Koss, J. W.; Witkin, J. M.; Li, X.; Overshiner, C.; Wafford, K. A.; Seidel, W.; Wang, X. S.; Heinz, B. A.; Swanson, S.; Catlow, J. T.; Bedwell, D. W.; Monn, J. A.; Mitch, C. H.; Ornstein, P. L. Discovery of $\quad(1 \mathrm{~S}, 2 \mathrm{R}, 3 \mathrm{~S}, 4 \mathrm{~S}, 5 \mathrm{R}, 6 \mathrm{R})$-2-amino-3-[(3,4-difluorophenyl)sulfanylmethyl]-4-hydroxy-bicy clo[3.1.0]hexane-2,6-dicarboxylic acid hydrochloride (LY3020371.HCl): a potent, metabotropic glutamate 2/3 receptor antagonist with antidepressant-like activity. J. Med. Chem. 2016, 59, 10974-10993.

(57) Eisenberg, D.; Luthy, R.; Bowie, J. U. VERIFY3D: assessment of protein models with threedimensional profiles. Methods Enzymol. 1997, 277, 396-404.

(58) Colovos, C.; Yeates, T. O. Verification of protein structures: patterns of nonbonded atomic interactions. Protein Sci. 1993, 2, 1511-1519. 
(59) Waterhouse, A.; Bertoni, M.; Bienert, S.; Studer, G.; Tauriello, G.; Gumienny, R.; Heer, F. T.; de Beer, T. A. P.; Rempfer, C.; Bordoli, L.; Lepore, R.; Schwede, T. SWISS-MODEL: homology modelling of protein structures and complexes. Nucleic Acids Res. 2018, 46, W296W303.

(60) McGuffin, L. J.; Shuid, A. N.; Kempster, R.; Maghrabi, A. H. A.; Nealon, J. O.; Salehe, B. R.; Atkins, J. D.; Roche, D. B. Accurate template-based modeling in CASP12 using the IntFOLD4TS, ModFOLD6, and ReFOLD methods. Proteins. 2018, 86, 335-344.

(61) Tong, W.; Wei, Y.; Murga, L. F.; Ondrechen, M. J.; Williams, R. J. Partial order optimum likelihood (POOL): maximum likelihood prediction of protein active site residues using 3D Structure and sequence properties. PLoS Comput. Biol. 2009, 5, e1000266.

(62) Harpsoe, K.; Isberg, V.; Tehan, B. G.; Weiss, D.; Arsova, A.; Marshall, F. H.; BraunerOsborne, H.; Gloriam, D. E. Selective negative allosteric modulation of metabotropic glutamate receptors - A structural perspective of ligands and mutants. Sci. Rep. 2015, 5, 13869.

(63) Hanwell, M. D.; Curtis, D. E.; Lonie, D. C.; Vandermeersch, T.; Zurek, E.; Hutchison, G. R. Avogadro: an advanced semantic chemical editor, visualization, and analysis platform. $J$. Cheminform. 2012, 4, 17.

(64) Sherman, W.; Beard, H. S.; Farid, R. Use of an induced fit receptor structure in virtual screening. Chem. Biol. Drug. Des. 2006, 67, 83-84.

(65) Sherman, W.; Day, T.; Jacobson, M. P.; Friesner, R. A.; Farid, R. Novel procedure for modeling ligand/receptor induced fit effects. J. Med. Chem. 2006, 49, 534-553.

(66) Farid, R.; Day, T.; Friesner, R. A.; Pearlstein, R. A. New insights about HERG blockade obtained from protein modeling, potential energy mapping, and docking studies. Bioorg. Med. Chem. 2006, 14, 3160-3173. 
(67) Wenlock, M. C.; Potter, T.; Barton, P.; Austin, R. P. A method for measuring the lipophilicity of compounds in mixtures of 10. J. Biomol. Screen. 2011, 16, 348-355.

(68) Di, L.; Kerns, E. H.; Hong, Y.; Chen, H. Development and application of high throughput plasma stability assay for drug discovery. Int. J. Pharm. 2005, 297, 110-119.

(69) Houston, J. B. Utility of in vitro drug metabolism data in predicting in vivo metabolic clearance. Biochem. Pharmacol. 1994, 47, 1469-1479.

(70) Collier, T.; Normandin, M.; El Fakhri, G; Vasdev, N. Automation of column-switching HPLC for analysis of radiopharmaceuticals and their metabolites in plasma. J. Nucl. Med. 2013, 54, 1133. (71) Hilton, J.; Yokoi, F.; Dannals, R. F.; Ravert, H. T.; Szabo, Z.; Wong, D. F. Column-switching HPLC for the analysis of plasma in PET imaging studies. Nucl. Med. Biol. 2000, 27, 627-30.

(72) Guehl, N. J.; Ramos-Torres, K. M.; Linnman, C.; Moon, S. H.; Dhaynaut, M.; Wilks, M. Q.; Han, P. K.; Ma, C.; Neelamegam, R.; Zhou, Y. P.; Popko, B.; Correia, J. A.; Reich, D. S.; Fakhri, G. E.; Herscovitch, P.; Normandin, M. D.; Brugarolas, P. Evaluation of the potassium channel tracer $\left[{ }^{18} \mathrm{~F}\right] 3 \mathrm{~F} 4 \mathrm{AP}$ in rhesus macaques. J. Cereb. Blood Flow Metab. 2020, 41, 1721-1733.

(73) Jenkinson, M.; Beckmann, C. F.; Behrens, T. E.; Woolrich, M. W.; Smith, S. M. Fsl. Neuroimage. 2012, 62, 782-790.

(74) Seidlitz, J.; Sponheim, C.; Glen, D.; Ye, F. Q.; Saleem, K. S.; Leopold, D. A.; Ungerleider, L.; Messinger, A. A population MRI brain template and analysis tools for the macaque. Neuroimage. 2018, 170, 121-131.

(75) Innis, R. B.; Cunningham, V. J.; Delforge, J.; Fujita, M.; Gjedde, A.; Gunn, R. N.; Holden, J.; Houle, S.; Huang, S. C.; Ichise, M.; Iida, H.; Ito, H.; Kimura, Y.; Koeppe, R. A.; Knudsen, G. M.; Knuuti, J.; Lammertsma, A. A.; Laruelle, M.; Logan, J.; Maguire, R. P.; Mintun, M. A.; Morris, E. D.; Parsey, R.; Price, J. C.; Slifstein, M.; Sossi, V.; Suhara, T.; Votaw, J. R.; Wong, D. F.; 
Carson, R. E. Consensus nomenclature for in vivo imaging of reversibly binding radioligands. $J$. Cereb. Blood Flow Metab. 2007, 27, 1533-9.

(76) Logan, J.; Fowler, J. S.; Volkow, N. D.; Wolf, A. P.; Dewey, S. L.; Schlyer, D. J.; MacGregor, R. R.; Hitzemann, R.; Bendriem, B.; Gatley, S. J.; Christman, D. R. Graphical analysis of reversible radioligand binding from time-activity measurements applied to $\left[N-{ }^{11} \mathrm{C}-\mathrm{methyl}\right]-(-)-$ cocaine PET studies in human subjects. J. Cereb. Blood Flow Metab. 1990, 10, 740-747. 


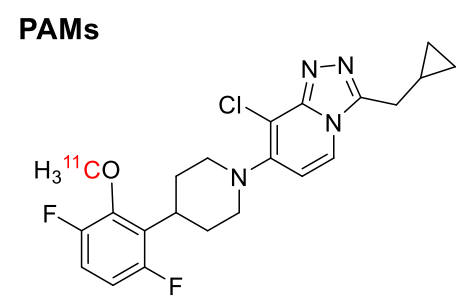

$3\left[{ }^{11} \mathrm{C}\right] J N J-42491293$

\section{NAMs}<smiles>C[OH+]c1ccc(-c2cc(C(N)=O)nc3cc(CN4C(=O)CCC4=O)ccc23)c(F)c1</smiles>

$7\left[{ }^{11} \mathrm{C}\right] \mathrm{QCA}$<smiles>C[OH+]c1cc(CN2CCc3c(-c4ccc(F)cc4F)cc(C(N)=O)nc3C2)ccn1</smiles>

$10\left[{ }^{11} \mathrm{C}\right] \mathrm{MG} 2-1904$

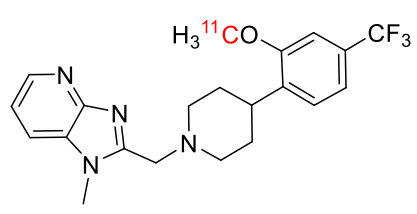

$4\left[{ }^{11} \mathrm{C}\right] \mathrm{mG} 2 \mathrm{P} 001$<smiles>C[OH+]c1ccc(-c2cc(C(N)=O)ncc2OCc2ccnc(C)c2)c(F)c1</smiles>

$8\left[{ }^{11} \mathrm{C}\right] \mathrm{MMP}$

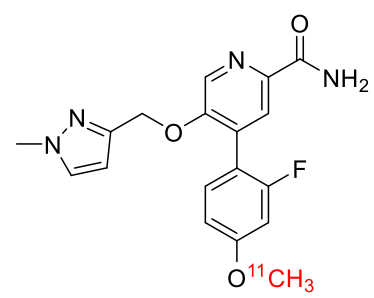

$11\left[{ }^{11} \mathrm{C}\right] \mathrm{MG} 2-1812$

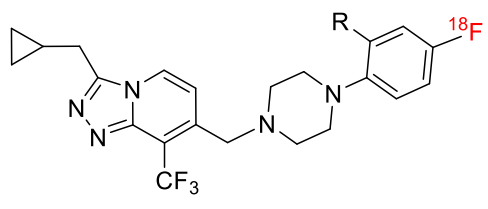

$5 \mathrm{R}=\mathrm{F},\left[{ }^{18} \mathrm{~F}\right] \mathrm{JNJ}-46356479$ $6 \mathrm{R}=\mathrm{Cl},\left[{ }^{18} \mathrm{~F}\right] \mathrm{mG} 2 \mathrm{P} 026$<smiles>[14CH3]n1ccc(COc2cnc(C(N)=O)cc2-c2ccc(F)cc2)n1</smiles>

$9\left[{ }^{11} \mathrm{C}\right] \mathrm{VU} 6001966$<smiles>[R]c1ccc(-c2cc(C(N)=O)nc3c2CCC(C)(C)O3)c(F)c1</smiles>

$12 \mathrm{R}=\mathrm{F}$;

$13 \mathrm{R}=\mathrm{OCH}_{3}$

Figure 1. Structures of the mGluR2 allosteric modulators. 

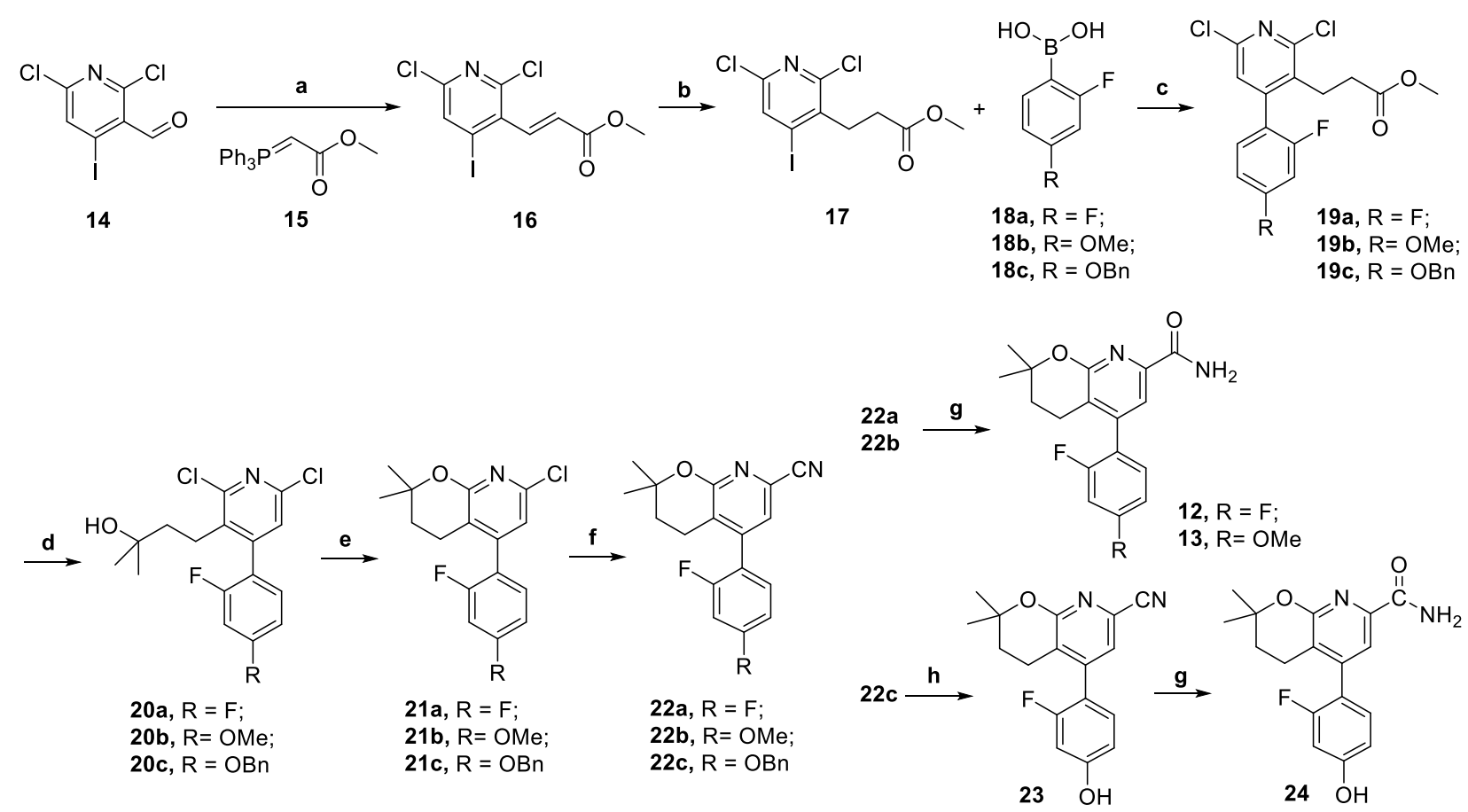

Scheme 1. Synthesis of compounds 12, 13 and 24. Reagents and conditions: (a) THF, $\mathrm{N}_{2}, 80{ }^{\circ} \mathrm{C}$,

2 h; (b) $\mathrm{RhCl}\left(\mathrm{PPh}_{3}\right)_{3}, \mathrm{H}_{2}, 40$ psi, rt, 2 d; (c) $\mathrm{Pd}(\mathrm{dppf}) \mathrm{Cl}_{2}, \mathrm{NaHCO}_{3}, 1$,4-dioxane/water, $100{ }^{\circ} \mathrm{C}, 3$

h; (d) $\mathrm{MeMgBr}\left(3.0 \mathrm{M}\right.$ in diethyl ether), THF, $0{ }^{\circ} \mathrm{C}, 1 \mathrm{~h}$; (e) $\mathrm{Cs}_{2} \mathrm{CO}_{3}$, DMA, $120^{\circ} \mathrm{C}$, overnight; (f)

$\mathrm{Zn}(\mathrm{CN})_{2}$, microwave, $160{ }^{\circ} \mathrm{C}, 30 \mathrm{~min} ;(\mathrm{g}) \mathrm{Na}_{2} \mathrm{CO}_{3} \cdot 1.5 \mathrm{H}_{2} \mathrm{O}_{2}$, acetone, water, rt, overnight; (h)

EtOAc, $\mathrm{H}_{2}, \mathrm{Pd} / \mathrm{C}(10$ wt.\%), rt, overnight. 
A

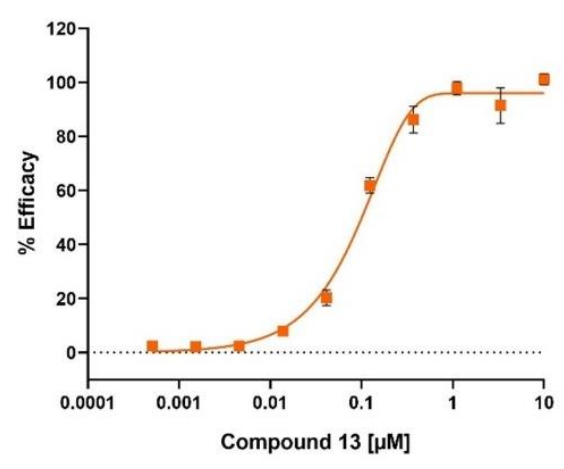

C

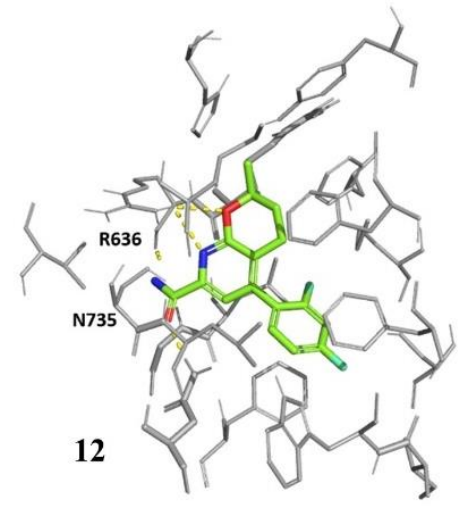

B
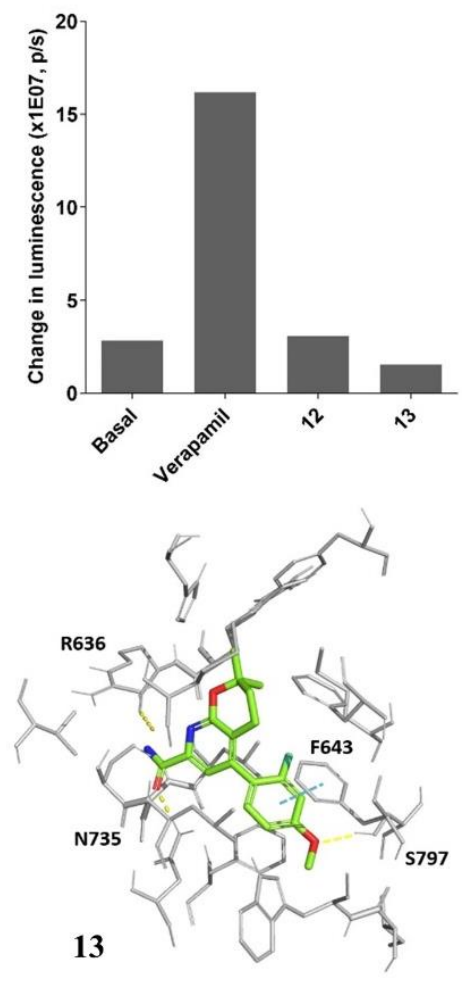

Figure 2. Characterization of compounds 12 and 13. (A) GPCR cAMP modulation result for compound 13; (B) Pgp-Glo ${ }^{\mathrm{TM}}$ assay; (C) snapshots of the docking poses for compounds 12 and 13. The key binding residues are shown in gray and the ones interacting with the ligand are labelled. The ligand atoms are rendered as carbon in green, nitrogen in blue, oxygen in red, and fluorine in cyan. Yellow dotted lines represent H-bonds and cyan dotted lines show $\pi$ - $\pi$ stacking. Pictures were rendered in PyMol 2.3.3. 
bioRxiv preprint doi: https://doi org/10.1101/2021.06.29.450413; this version posted June 30, 2021. The copyright holder for this preprint (which was not certified by peer review) is the author/funder, who has granted bioRxiv a license to display the preprint in perpetuity. It is made available under aCC-BY-NC-ND 4.0 International license.

Table 1. Summary of the in vitro and in silico results of compounds $\mathbf{1 2}$ and $\mathbf{1 3}$

\begin{tabular}{cccccccc}
\hline Comp. & cLogP & $\operatorname{LogD}_{7.4}$ & $\mathrm{IC}_{50}(\mathrm{nM})$ & $\begin{array}{c}\text { Plasma } \\
\text { stability }\end{array}$ & $\begin{array}{c}\text { Microsome } \\
\text { stability }\end{array}$ & $\begin{array}{c}\text { Change in } \\
\text { luminescence }(\mathrm{p} / \mathrm{s})\end{array}$ & $\begin{array}{c}\text { Docking } \\
(\mathrm{kcal} / \mathrm{mol})\end{array}$ \\
\hline $\mathbf{1 2}$ & 4.3 & 2.81 & 6.0 & 95.3 & 94.5 & $3.07 \mathrm{E} 7$ & -11.74 \\
$\mathbf{1 3}$ & 4.25 & 2.94 & 93.2 & 92.2 & 47.8 & $1.53 \mathrm{E} 7$ & -11.00 \\
\hline
\end{tabular}




\section{Synthesis of $\left[{ }^{11} \mathrm{C}\right] /\left[{ }^{18} \mathrm{~F}\right] 12$ :}
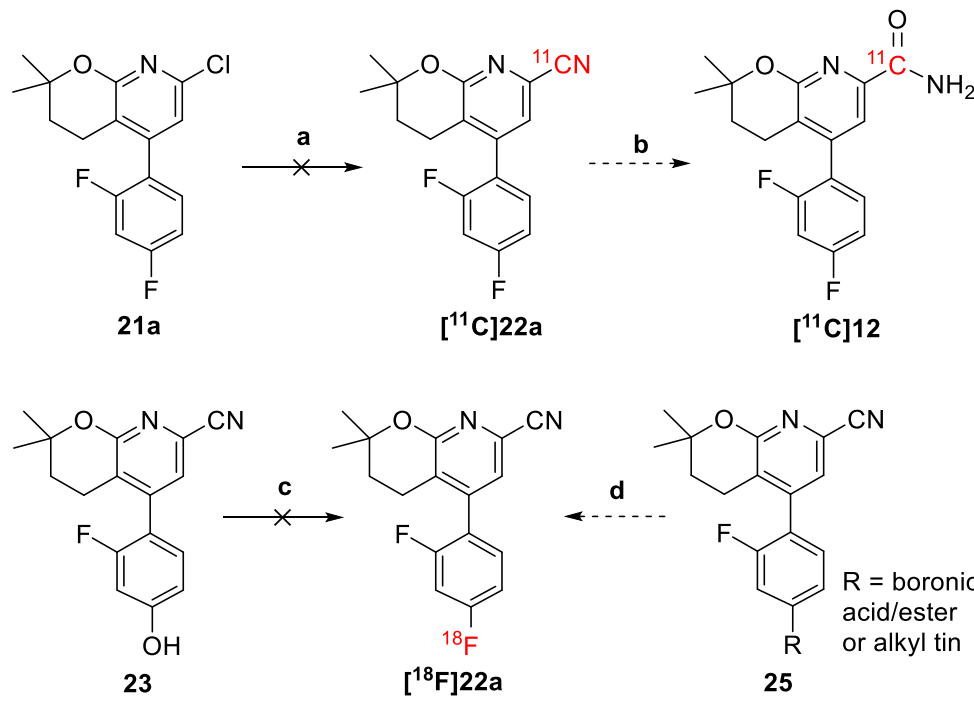

\section{Synthesis of $\left[{ }^{11} \mathrm{C}\right] 13$ :}

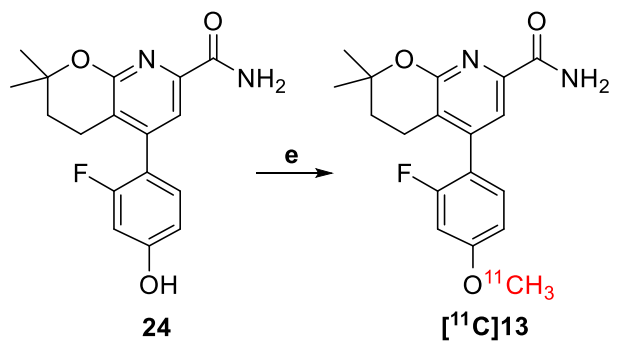

Scheme 2. Radiolabeling strategies for compounds 12 and 13. Reagents and conditions: (a) 21a $(0.32 \mu \mathrm{mol}), \mathrm{Pd}\left(\mathrm{PPh}_{3}\right)_{4}(0.9 \mu \mathrm{mol}),\left[{ }^{11} \mathrm{C}\right] \mathrm{HCN}(3.5 \mathrm{GBq}), \mathrm{DMF}(0.1 \mathrm{~mL}), 160{ }^{\circ} \mathrm{C}, 5$ or $10 \mathrm{~min} ;$ (b) $\mathrm{Na}_{2} \mathrm{CO}_{3} \cdot 1.5 \mathrm{H}_{2} \mathrm{O}_{2}$ or $35 \% \mathrm{H}_{2} \mathrm{O}_{2}$, rt, 2 min; (c) i. $23(15 \mu \mathrm{mol}), \mathrm{CpRu}(\mathrm{COD}) \mathrm{Cl}(45 \mu \mathrm{mol}), \mathrm{EtOH}$ $(50 \mu \mathrm{L}), 85{ }^{\circ} \mathrm{C}, 30 \mathrm{~min}$; ii. chloroimidazolium chloride $(45 \mu \mathrm{mol}), \mathrm{CH}_{3} \mathrm{CN}(150 \mu \mathrm{L}),{ }^{18} \mathrm{~F}^{-}(1.5$ GBq), DMSO $(150 \mu \mathrm{L}), 125^{\circ} \mathrm{C}, 30 \mathrm{~min}$; (d) tetraethylammonium bicarbonate, ${ }^{18} \mathrm{~F}^{-},\left[\mathrm{Cu}(\mathrm{OTf})_{2} \mathrm{py}_{4}\right]$, DMF, $130{ }^{\circ} \mathrm{C}, 10 \mathrm{~min}$; (e) 24 (1.6 $\left.\mu \mathrm{mol}\right),\left[{ }^{11} \mathrm{C}_{\mathrm{CH}} \mathrm{I}(7.4-74 \mathrm{GBq}), 0.5 \mathrm{~N} \mathrm{NaOH}(3.0 \mu \mathrm{L}), \mathrm{DMF}\right.$ (0.35 mL), $80{ }^{\circ} \mathrm{C}, 3 \mathrm{~min}$. 
bioRxiv preprint doi: https://doi.org/10.1101/2021.06.29.450413; this version posted June 30, 2021. The copyright holder for this preprint (which was not certified by peer review) is the author/funder, who has granted bioRxiv a license to display the preprint in perpetuity. It is made available under aCC-BY-NC-ND 4.0 International license.

A

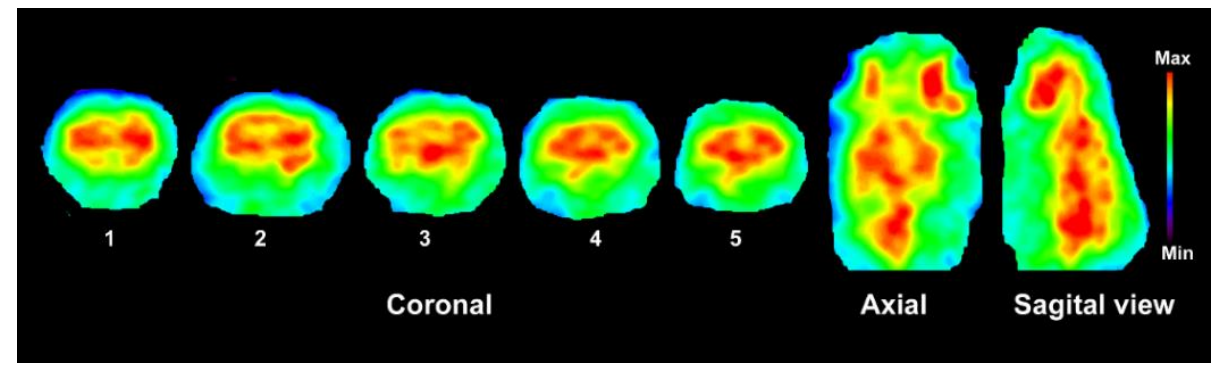

B

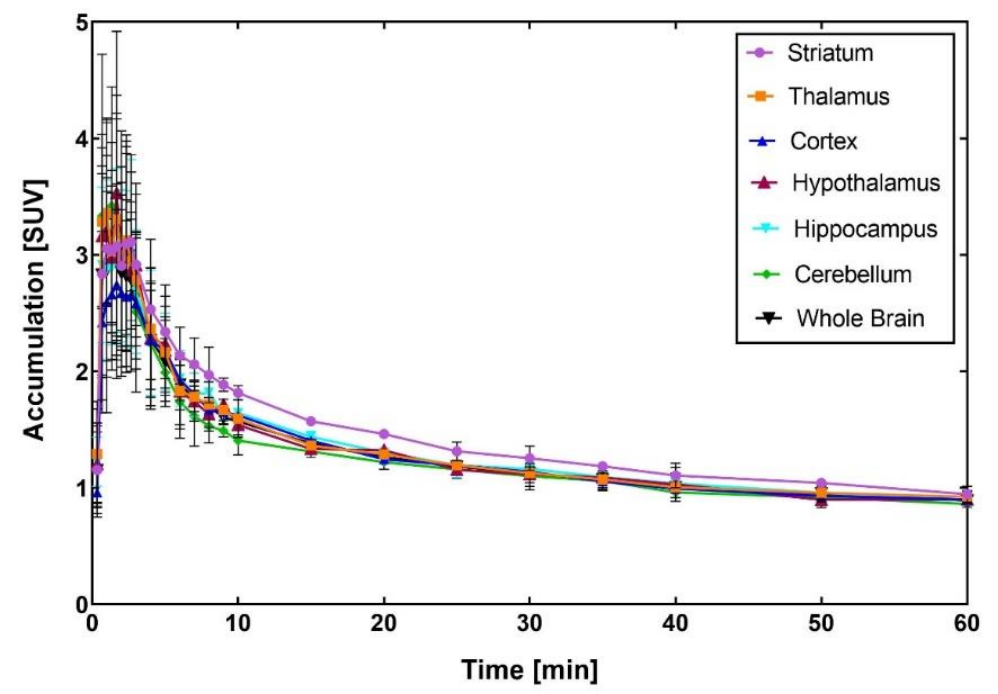

C

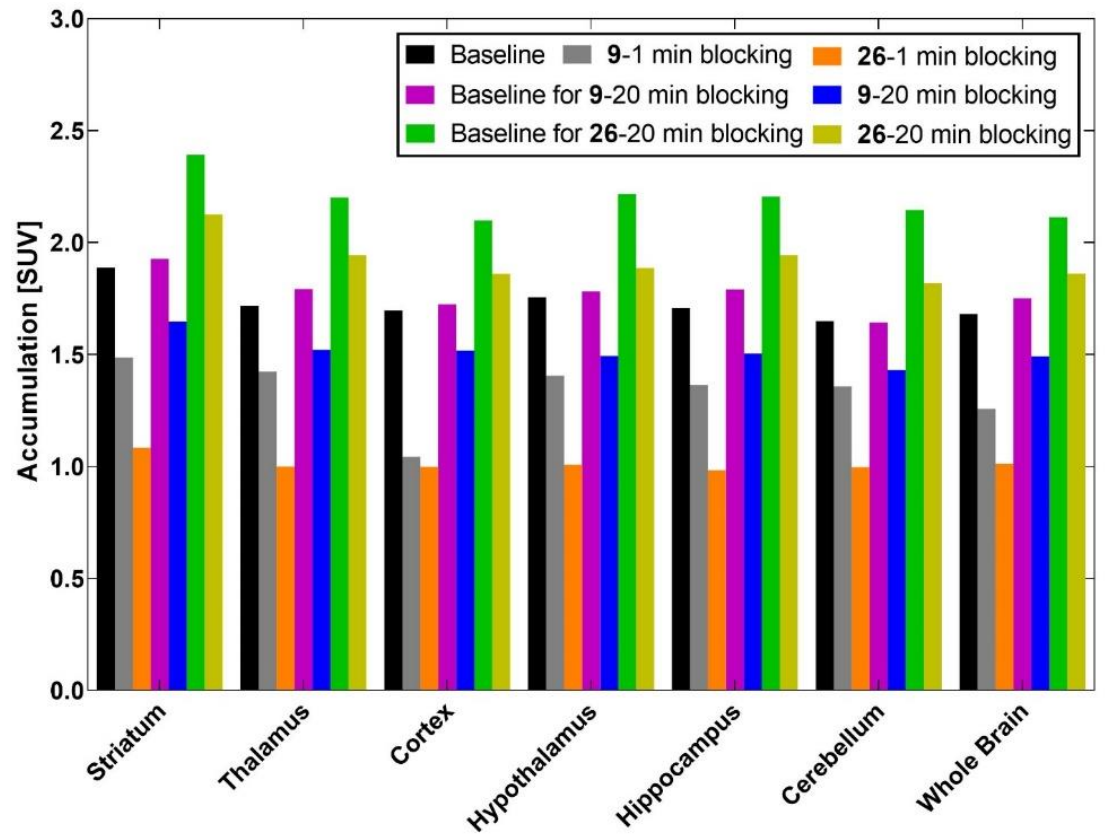


Figure 3. Preliminary PET imaging results of $\left[{ }^{11} \mathrm{C}\right] \mathbf{1 3}$ in rat brain. (A) Summed PET images at the time interval of 1-30 min. Coronal levels show striatum (1), cingular cortex, striatum, thalamus, hypothalamus (2), cortex, hippocampus, thalamus (3), and cerebellar structures (4 and 5); (B) Representative time-activity curves of $\left[{ }^{11} \mathrm{C}\right] \mathbf{1 3}$ across the regions of interest; $(\mathbf{C})$ Accumulation of radioactivity during the 2-30 min window after pretreatment with VU6001966 (9) or MNI-137 (26) administered $1 \mathrm{~min}$ or $20 \mathrm{~min}$ before radioligand. The "Baseline" SUV values were the average of three baseline studies. Pictures were rendered from Prism 9.0. 


\section{A Ratio plasma/whole blood}

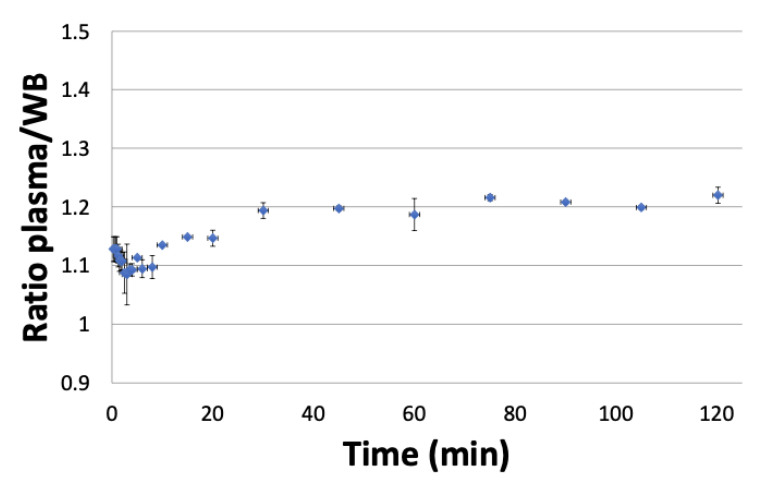

C Radiotracer metabolism

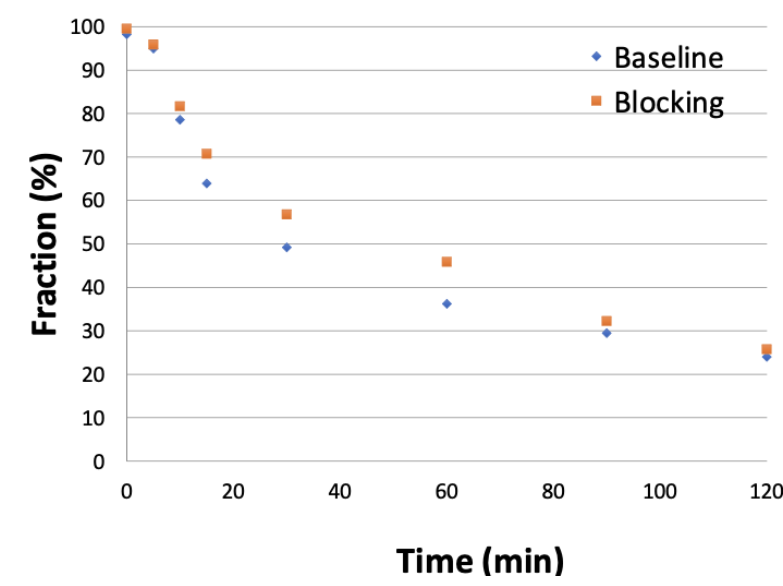

\section{B Baseline Radiochromatogram}

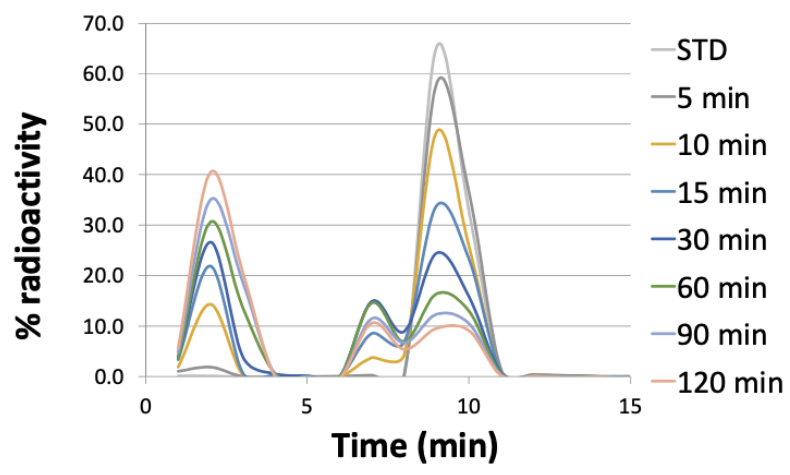

D Metabolite-corrected plasma

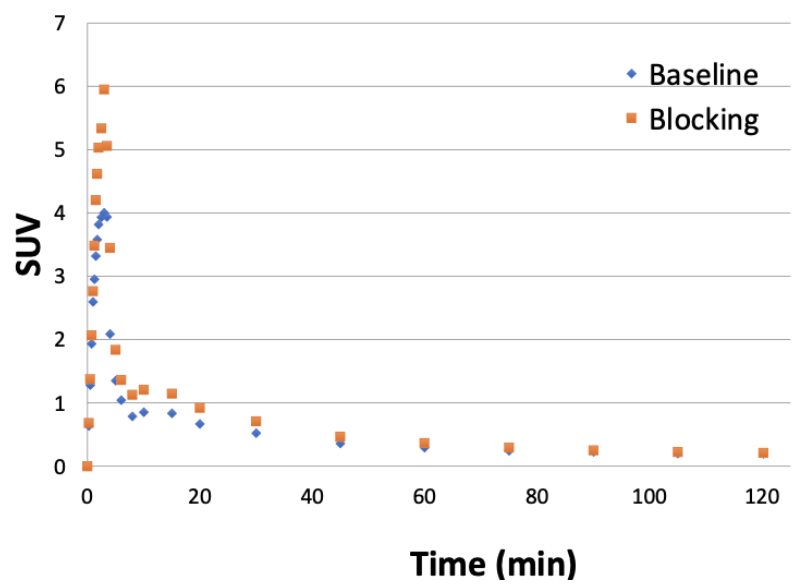

Figure 4. $\left[{ }^{11} \mathrm{C}\right] \mathbf{1 3}$ analysis in arterial blood. (A) Plasma/Whole blood ratios. (B) Representative radiochromatogram of plasma samples from baseline study. (C) Individual time course of percent parent in plasma (\%PP). (D) Individual metabolite-corrected SUV time courses in plasma. 
bioRxiv preprint doi: https://doi.org/10.1101/2021.06.29.450413; this version posted June 30, 2021. The copyright holder for this preprint (which was not certified by peer review) is the author/funder, who has granted bioRxiv a license to display the preprint in perpetuity. It is made available under aCC-BY-NC-ND 4.0 International license.

A

Baseline 2T4k1v model fits

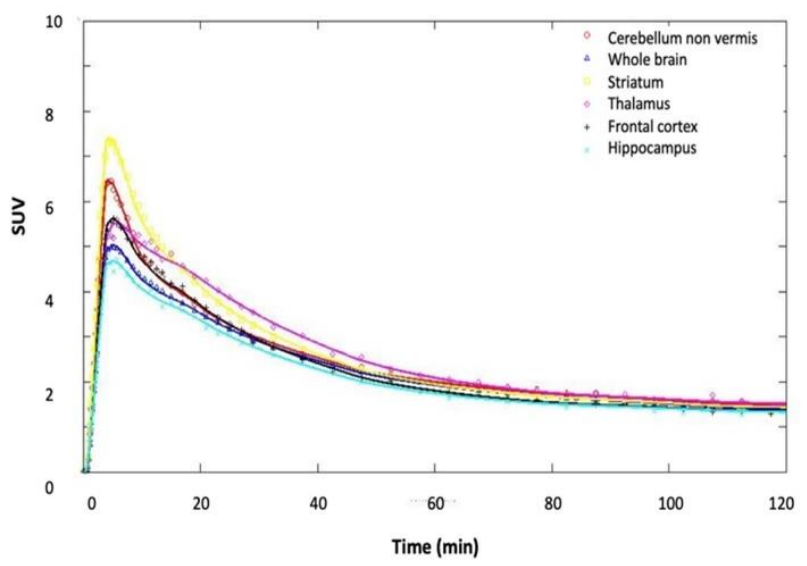

Blocking 2T4k1v model fits

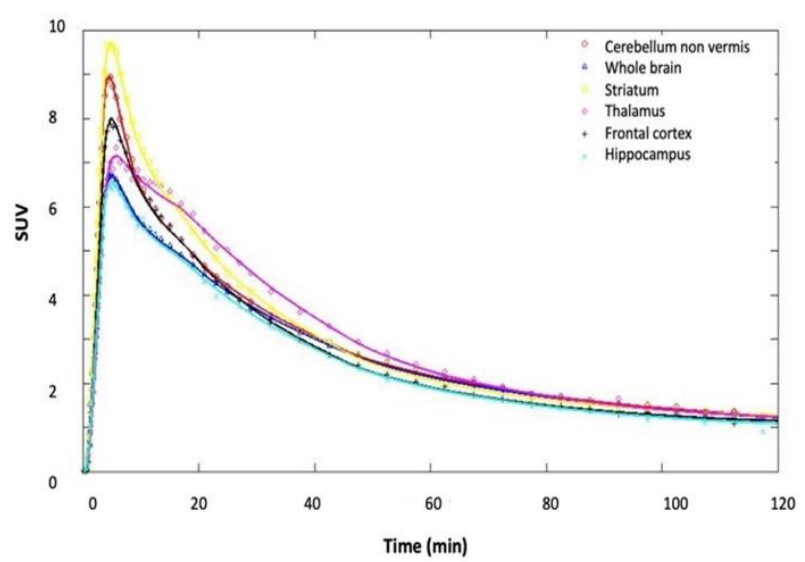

Baseline Logan model fits (30 $\min \mathbf{t}^{*}$ )

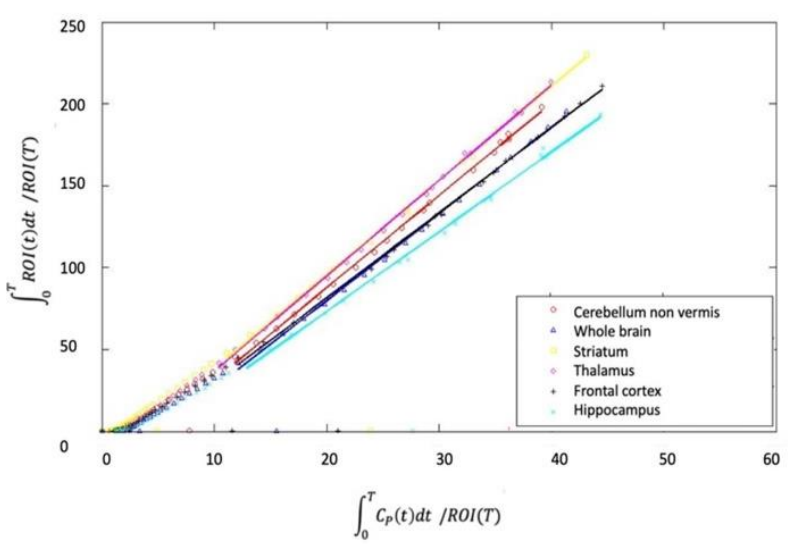

Blocking Logan model fits (30 min t*)

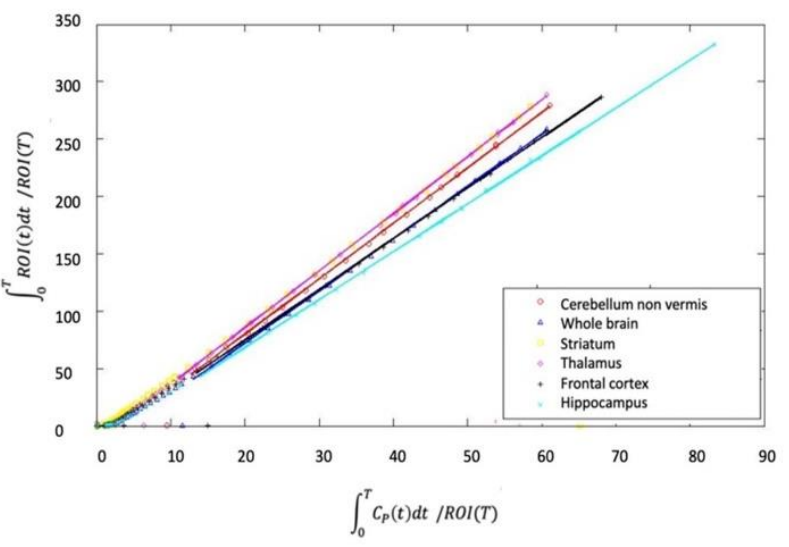

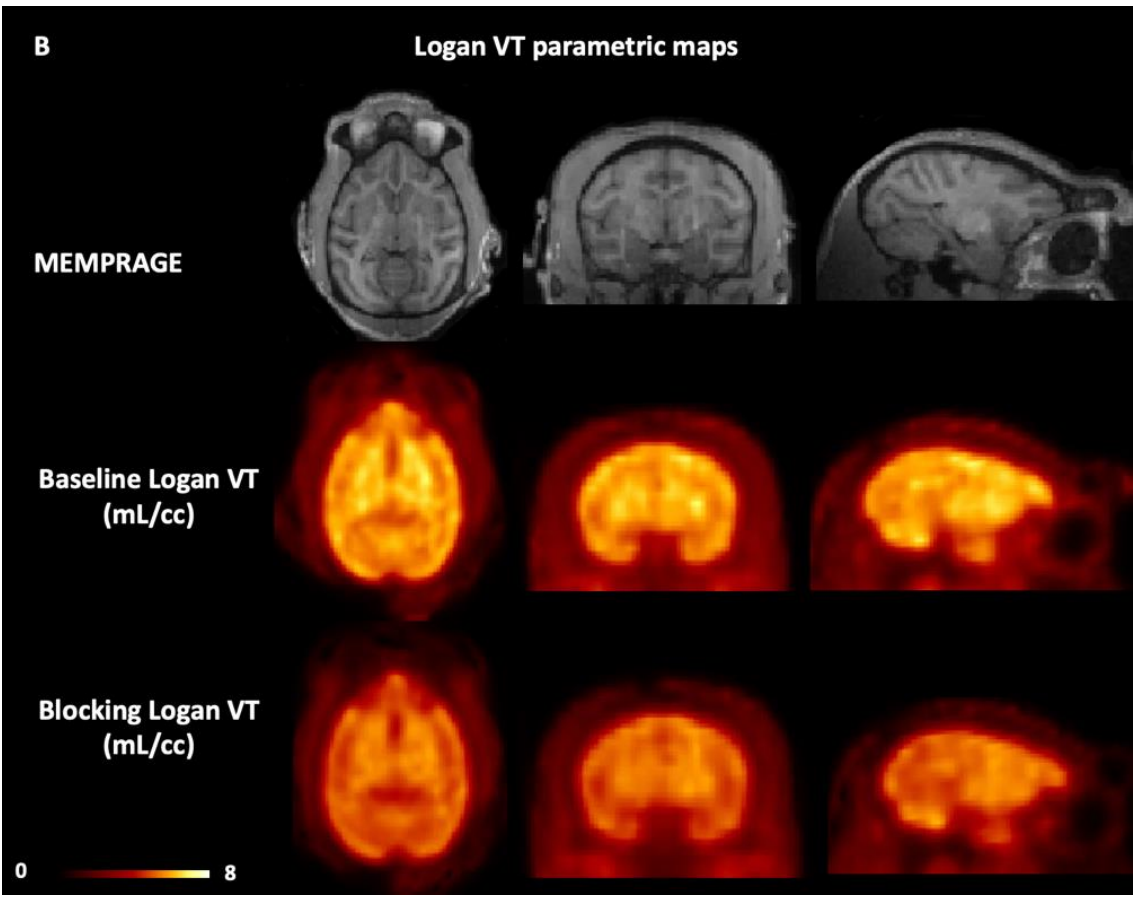


C

Logan VT Bar Graphs

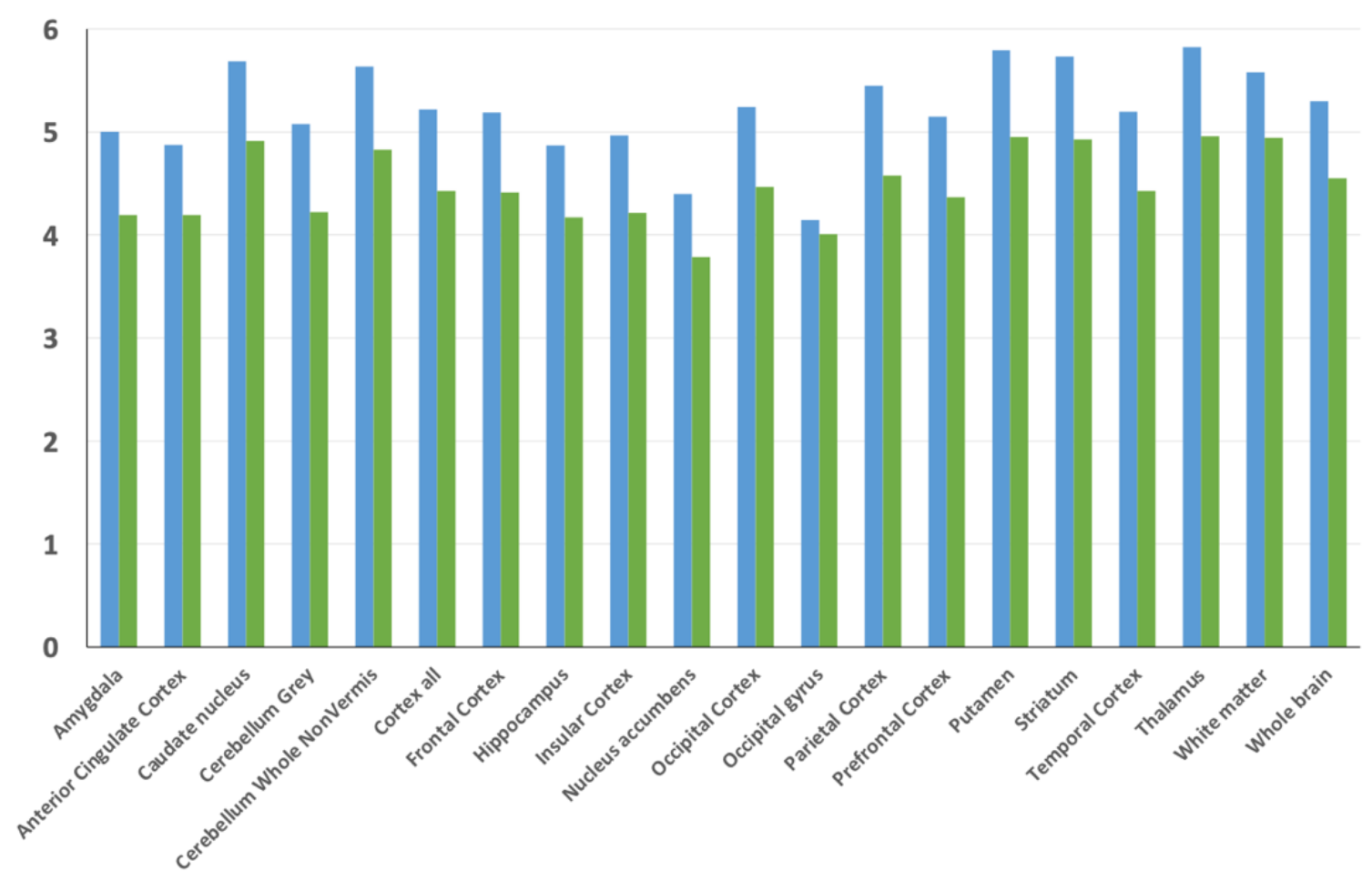

" Moollyg baseline Logan VT M Moollyg blocking Logan VT

Figure 5. Characterization of $\left[{ }^{11} \mathrm{C}\right] \mathbf{1 3}$ in the nonhuman primate brain. (A) 2-tissue compartment model $(2 \mathrm{~T} 4 \mathrm{k} 1 \mathrm{v})$ fits in the six brain regions (left) and Logan plots (right) for $\left[{ }^{11} \mathrm{C}\right] \mathbf{1 3}$ in the baseline and blocking experiments. (B) Structural MRI (MEMPRAGE) and $\left[{ }^{11} \mathrm{C}\right] \mathbf{1 3}$ Logan $V_{T}$ images for the baseline (middle) and blocking studies (bottom). (C) Logan $V_{T}$ values bar graph obtained when using 120 min of data and $t^{*}$ of 30 min under baseline and blocking conditions. 